\title{
Die Stämme des Tierreichs in ihrer systematischen Gliederung
}

\author{
Boettger, Caesar R.
}

Veröffentlicht in:

Abhandlungen der Braunschweigischen Wissenschaftlichen Gesellschaft Band 4, 1952 , S. $238-300$

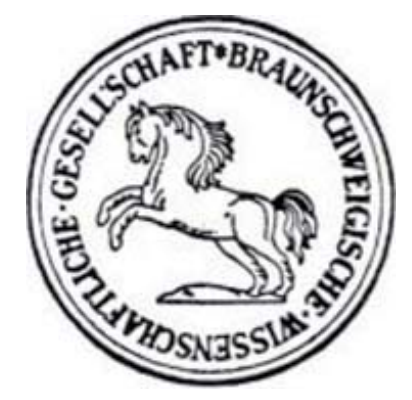

Friedr. Vieweg \& Sohn, Braunschweig 


\title{
Die Stämme des Tierreichs in ihrer systematischen Gliederung
}

\author{
Von Caesar R. Boettger \\ The Classification of the different branches of the \\ Animal Kingdom
}

The author gives a short survey on the changes in our opinions about the classification of the different branches of animals since the time of Linnaeus. It is necessary to take into consideration not only the species now existing, but also the extinct ones. Therefore a close collaboration between the zoologists and palaeontologists is to be desired in this respect. The arrangement of the different groups of Metazoa doum to the suborders may be examined at the conclusion of the German text. The commonly employed name of Decapoda for an order in the subclass of Dibranchiate Cephalopods has been substituted by Decabrachia, because the term Deca poda is preoccupied by Deca poda, suborder of the Malacostraca, subclass of erayfish; together with Decabrachia the new name of Octobrachia has been proposed for Octopoda. The subkladus for the Crustacea sens. lat., often quoted as Branchiata, is named Diantennata in connection with the peculiarities expressed by this name.

Es ist Aufgabe der biologischen Systematik, die Lebewesen übersichtlich in Einheiten zusammenzufassen und sie nach phylogenetischen Gesichts. punkten zu gliedern.

Die stammesgeschichtliche Forschnng ist ein Gebiet von erbeblicher Reichweite, und Erkenntnisse verschiedenster biologischer Arbeitsrichtungen haben im Laufe der Zeit unsere Anschauungen über die Systematik der Lebewesen wesentlich beeinfluBt.

I.

Eine Systematik nach neuzeitlichen Gesichtspunkten war erst möglich, nachdem man sich entschlossen hatte, Arten mit international anerkannten Namen zu belegen. Nur durch das Hilfsmittel einer brauchbaren Nomenklatur gelang es, sich in dem ungeheuren Formenreichtum der Lebewesen zurechtzufinden. Es ist das große Verdienst Carl v. Linnés (1707-1778), eine gegenüber früheren Versuchen erhebliche Vorteile aufweisende und doch einfache Nomenklatur vorgeschlagen und die Arten zu einem verständlichen, katalogartigen System geordnet zu haben. Diese Namengebung durch C. v. Linné fand rasch Anerkennung und Verbreitung. Aus ihr entwickelte sich die heutigentags allgemein gebräuchliche wissenschaftliche Nomenklatur, die als Grundlage auf die Editio $X$ von Linnés Systema Naturae aus dem Jahr 1758 aufbant. Die Möglichkeit einer kurzen prägnanten Bezeichnung von Funden gab der Erforschung der einzelnen Arten einen bedeutsamen Auftrieb, und man ist wohl berechtigt, die Systematik als Wissenschaft mit C. v. Linné beginnen $\mathrm{zu}$ lassen. 
Doch phylogenetische Gesichtspunkte lagen C. v. Linné noch vollständig fern. Er bekennt 1751 in seiner Philosophia botanica ganz eindeutig, daß es so viele Arten gibt, als verschiedene Formen am Anfang geschaffen wurden. Er bemühte sich, diese möglichst vollständig zu erfassen. Bei seiner Gruppierung der Arten in Gattungen, Ordnungen und Klassen ließ er sich allein von Gründen der Zweckmäßigkeit leiten. Dabei bewertete er oft Merkmale an bevorzugter Stelle, denen nach unserer heutigen Auffassung eine solche Bedeutung nicht zukommt. Erst mit zunehmender Verfeinerung der Arbeitsmethoden ist es allmählich gelungen, die vergleichend-anatomischen Grundlagen für die Erkenntnis der Zusammenhänge in der Mannigfaltigkeit der Organisation des Tierkörpers zu erlangen. So ist es verständlich, daß der Mensch bei der Beurteilung anderer Wesen zunächst Merkmale, die er von seinem eigenen Körper her kannte, überbewertete und außerdem unwillkürlich weniger scharf gliederte, je ferner die Lebewesen dem Menschen und seiner Umwelt standen. Es ist das durchaus dieselbe Erscheinung, wenn der Europäer die Menschen seiner Heimat sehr genau unterscheidet, während für ihn die Individuen anderer Menschenrassen, beispielsweise die Neger, zuerst alle gleich aussehen, bis er allmählich die Unterschiede zwischen ihnen erkennt.

C. v. Linné unterschied 3 Reiche, die der Steine, der Pflanzen und der Tiere. Das Reich der Tiere ordnete er in 6 Klassen:

I. Klasse: Mammalia. Herz aus 2 Vorkammern und 2 Herzkammern; rotes, warmes Blut; lebendgebärend.

II. ", Aves. Herz aus 2 Vorkammern und 2 Herzkammern; rotes, warmes Blut; eierlegend.

III. "Amphibia. Herz aus 1 Vorkammer und 1 Herzkammer; rotes, kaltes Blut; wechselweise mit Lungen atmend.

IV. " Pisces. Herz aus 1 Vorkammer und 1 Herzkammer; rotes, kaltes Blut; mit äußeren Kiemen.

V. " Insecta. Einfaches Herz; weiße, kalte Körperflüssigkeit; gegliederte Fühler.

VI. "Vermes. Einfaches Herz; weiße, kalte Körperflüssigkeit; ungegliederte Fühler.

In dieser Gruppierung kommt eine homozentrische Einstellung klar zum Ausdruck, wie sie für die damalige Zeit charakteristisch war. Allein die beiden ersten Klassen der Mammalia (Säugetiere) und Aves (Vögel) umfassen Tiere, die auch wir noch in je einer Klasse zusammenfassen, wobei allerdings zu bedenken ist, da B man gegenwärtig noch mehrere höhere Kategorien oberhalb der Klassen annimmt. In der dritten Klasse der Amphibien sind Arten enthalten, die man gegenwärtig in 4 verschiedenen Klassen unterbringt, anßer den Amphibia (Lurche) und Reptilia (Kriechtiere) noch die Cyclostomata (Rundmäuler), sowie von Fischen die Haie, Rochen und Störe. Den Rest der Fische stellte C. v. Linné in seine rierte Klasse Pisces. Diesen 4 ersten Klassen von Linnés System gehören also diejenigen Tiere an, die heutigentags in einem Kladus Vertebrata (Wirbeltiere) vereinigt werden. Die fünfte Klasse Insecta in Linnés Auffassung enthölt nicht nur die heute zu den Insekten gestellten Arten, sondern auch Krebse und Spinnen, 
also diejenigen Tiere, die einen weiteren, mehrere Klassen umfassenden Kladus Arthropoda bilden. Alle übrigen Tiere, für die doch in unserem auf phylogenetischer Grundlage aufgebauten System so mannigfaltige Gruppen geschaffen werden mußten, rechnet C. v. Linné sämtlich in seine sechste Klasse Vermes (Würmer). Diese enthält mit der Grattung Volvox L. sogar auch Arten, die jetzt nicht mehr als Tiere angesehen werden.

Die in Linnés Klassifikation auffällige systematische Überbewertung der Wirbeltiere hat dann vor allem ihren Ausdruck in der von Lamarck vorgenommenen Gegenüberstellung von Vertebrata und Evertebrata gefunden, welche Einteilung in der volkstümlichen Zoologie bis in die Gegenwart fortwirkt, so sehr auch die Wissenschaft von ihr abgerückt ist.

\section{II.}

Verschiedene neue Anschauungen haben dann diese Systematik in Linnés Sinn bald weitgehend beeinflußt. Zunächst erkannte man, daß die früher als tierischen Gestalten ähnliche Steine, als lusus naturae gedeuteten Fossilien tatsächlich auf frühere Lebewesen zurückzuführen sind, die nun auch systematisch zu berücksichtigen waren. Als die sich rasch entwickelnde Paläontologie Kenntnis über zahlreiche nicht mehr existierende Tiere und Pflanzen aus verschiedenen Erdschichten vermittelte, mußte aber die noch von C. v. Linné vertretene Annahme eines einzigen Schöpfungsaktes revidiert werden. Statt diesem nahm man nun mehrere Neuschöpfungen an, die nach wiederholten, alles Leben vernichtenden, sintflutartigen Naturereignissen erfolgten. Der hauptsächliche Vertreter dieser sogenannten ,Katastrophenlehre" war G.L.C.F.D. Baron de Cuvier (1769-1832). Auf Grund seines gründlichen vergleichend-anatomischen und paläontologischen Wissens konnte er aber dennoch die Baupläne der Tiere in Reihen anordnen, die vom Einfachen zum Komplizierten anstiegen. Er wies ferner darauf hin, daß die fossilen Tiere umso mehr denjenigen der lebenden Fauna ähnlicher wurden, je jünger die geologischen Ablagerungen waren. Doch nach den Ursachen dieser auffälligen Erscheinung fragte er nicht.

Diesen großen Gedanken dachte ein anderer, nämlich J.B.A.P. Monet de Lamarck (1744-1829). Er sprach erstmalig 1809 in seiner Philosophie zoologique eindeutig aus, da $\beta$ solche vom Einfachen zum Komplizierten aufsteigende Reihen Ausdruck einer Blutsverwandtschaft ihrer Glieder sind, daß ferner eine Spezialisierung der Formen durch allmähliche Wandlung erfolgt sein muB und daher letzten Endes alle Tiere auf wenige Stammformen zurückgeführt werden können. Die Ursachen für eine derartige Wandlung der Lebewesen hat allerdings damals Lamarck noch nicht richtig erkannt. Er meinte irriger Weise, sie in einer Vererbung erworbener Eigenschaften gefunden zu haben, welche Annahme später erhebliche Verwirrungen hervorrufen sollte; solche Gedankengänge können aber nach unseren heutigen Kenntnissen nicht scharf genug abgelehnt werden, weshalb in ihrer Auswirkung auch noch in der Gegenwart das Andenken an Lamarck leider manchmal getrübt wird. Obwohl diese große Erkenntnis von der Verwandtschaft und Wandelbarkeit der Arten zunächst wieder vergessen wurde, übte sie doch später auf die verschiedensten Wissenszweige einen überragenden EinfluB aus. Auch die biologische Systematik konnte sich ihr nicht entziehen. Durch die 
Aufnahme phylogenetischer Probleme in ihren Aufgabenkreis wurde das Forschungsgebiet der biologischen Systematik wesentlich erweitert, und diese wuchs über den Rahmen einer rein beschreibenden Wissenschaft hinaus.

Zum endgültigen Durchbruch gelangten die Gedankengänge von der $A b$ stammung der Lebewesen durch C. R. Darwin (1809-1882) mit seiner Descendenztheorie. Im Jahr 1859 veröffentlichte er sein Buch über "The origin of the species by means of natural selection". Eine Entstehung neuer Arten und die offensichtlich vielfachen zweckmäßigen Anpassungen erklärte C. R. Darwin durch seine sogenannte Selektionstheorie, die Lehre des eine Auslese verursachenden Kampfes ums Dasein und die geschlechtliche Zuchtwahl. Durch ein umfangreiches Beweismaterial wurde in der Folgezeit die neue Lehre gesichert.

Den Entwicklungsvorgang im einzelnen zu analysieren, gelang aber erst, als kurz nach der vergangenen Jahrhundertwende die durch eine Veröffentlichung aus dem Jahr 1865 festgelegten Arbeiten G. Mendels (1822-1884) wieder entdeckt wurden. Auf den Ergebnissen dieser Untersuchungen aufbauend, entwickelte sich mit der Zeit eine umfangreiche neue Wissensehaft, die Genetik. Frst als man allmählich im einzelnen die Vererbungsfaktoren beurteilen lernte, bekam man Verständnis für die Möglichkeiten einer Einstellung der Lebewesen in ihre Umwelt und für die große Plastizität des Lebens. Nunmehr wurde es auch begreiflich, daß beispielsweise nicht alles am Tier ,Zweckmäßig“ zu sein braucht, was auch gar nicht der Ansicht des vorsichtigen, genialen C. R. Darwin entsprach, was aber übereifrige Verfechter seiner Lehre überall zu erkennen glaubten. Eine solche Annahme konnte schon deshalb nicht den Tatsachen entsprechen, weil ebenso wie die Genkombination im Vererbungsvorgang auch das Auftreten neuer Mutanten durchaus ungerichtet erfolgt. Außerdem haben Laboratoriumsversuche über die Beeinflussung des Genbestandes der Geschlechtszellen durch bestjmmte Einwirkungen physikalischer wie chemischer Natur ergeben, daß der größte Teil der dabei erzeugten Mutanten überhaupt nicht lebensfähig ist und mehr oder weniger lange Zeit vor der Geschlechtsreife zugrunde geht. Allgemein bleiben unter den lebensfähigen Mutanten alle diejenigen erhalten, deren Merkmale sich ,nicht schädlich" für das Individuum auswirken. Es können manchmal an Biotopen mit weniger scharfen Auslesebedingungen für eine Art auch recht verschiedene Mutanten erhalten bleiben. So bieten mitunter Inseln manchen Tieren optimale Daseinsbedingungen, weil sie dort vor Feinden weitgehend geschützt sind; beispielsweise hätte die Entstehung der auf Neu-Guinea beheimateten Paradiesvögel auf einem Kontinent infolge des stärkeren Kampfes ums Dasein wahrscheinlich schwerlich erfolgen können. Wenn sich jedoch unter den vorkommenden Mutanten eine mit sich zweckmäBig auswirkenden Eigenschaften befindet, so wird sie sich zweifellos im Kampf ums Dasein leichter durchsetzen als die anderen. Auch ist es möglich, daB durch das Auftreten einer Mutante mit neuen Eigenschaften neuer Lebensraum besiedelt werden kann, den die Art bisher nicht auszunutzen vermochte, weil ihr die körperlichen Voraussetzungen fehiten. Infolge dieser genetischen Betrachtungsweise wird es verständlich, auf welche Weise im Verlauf der erdgeschichtlichen Entwicklung Veränderungen im Erbgefüge der Organismen stattgefunden haben können. Der für C. v. Linné auf Grund der Annahme eines

Wissenschaftl. Abhandi. IV, 1952 
Schöpfungsaktes feststehende Artbegriff wird daher zeitlich begrenzt und eine phylogenetische Beziehung zwischen Arten verständlich gemacht.

\section{III.}

In Zusammenhang mit dem sehr unterschiedlichen Grad der Verwandtschaft der einzelnen Lebewesen untereinander ist es einleuchtend, daß die von C. v. Linné in seinem System verwendete Einteilung in Klassen, Ordnungen und Arten in der Gegenwart nicht mehr ausreicht und durch eine Hinzunahme weiterer Stufen ergänzt werden muß, um die verschiedenen Abstände zwischen den Gruppen genauer ausdrücken zu können. Allgemein gebräuchlich sind folgende systematische Kategorien:

Regnum (Reich)

Divisio (Abteilung)

Phylum (Stamm)

Kladus (Kreis)

Classis (Klasse)

Ordo (Ordnung)

Familia (Familie)

Genus (Gattung)

Species (Art).

Jede dieser Einheiten kann wieder durch Vorsetzen der Silbe Sub- noch weiter unterteilt werden. Die Schaffung zusätzlicher Unterscheidungen durch Überordnen neuer Gruppen mit der Vorsilbe Super- läßt sich wohl im allgemeinen vermeiden, wie aus der in dieser Arbeit gegebenen Einteilung hervorgehen dürfte. Nur in Ordnungen mit besonders großem Bestand an Familien, wie beispielsweise bei den Insekten-Ordnungen der Käfer, Hymenopteren, Schmetterlinge und Dipteren, erscheint es zweckmäßig, innerhalb der Ordnungen Überfamilien zu unterscheiden.

Manchmal hat man noch weitere Kategorien eingeführt, so Legio (zwischen Classis und Ordo), Stirps (zwischen Ordo und Familia), Tribus (zwischen Familia und Genus) und Sectio (zwischen Genus und Species). Am ehesten läßt sich noch eine Gliederung umfangreicher Unterfamilien von Insekten (etwa der Hymenoptera) in Tribus rechtfertigen, wenn vielleicht auch auf sie verzichtet werden kann. Das gilt in noch erhöhtem Maße für eine Einteilung der Subgenera in Sectionen. Die Begriffe Legio und Stirps aber sind nach meiner Ansicht sicher zu entbehren.

Durch eine übertriebene Gliederung des Systems wird aber die Übersicht unnötig erschwert, was unbedingt vermieden werden sollte. Gelegentlich haben einzelne Zoologen, ror allem manche Spezialisten, die eine Verbindung mit der allgemeinen Wissenschaft weitgehend verloren haben, in ihrem Bestreben nach allzu genauer Bezeichnung des Verwandtschaftsgrades einzelner Gruppen zueinander, die Systematik durch Aufstellen zahlreicher Unterabteilungen und damit auch die Nomenklatur über Gebühr belastet. Beispielsweise stehen in der Klasse Mammalia (Säugetiere) sich die Unterklassen Marsupialia (Beuteltiere) und Placentalia (Plazentasäugetiere) untereinander zweifellos näher als der Unterklasse Prototheria (Ursäugetiere); dennoch wäre es fehl am Platz, innerhalb der Säugetiere zunächst ron den Prototherien noch eine Gruppe abzutrennen und diese dann erst 
in Beuteltiere und Plazentasäugetiere zu gliedern. Der Zoologe weiß ohnehin über den Verwandtschaftsgrad Bescheid, oder er kann sich leicht in der ein-. schlägigen Literatur darüber unterrichten. Sonst aber wird man es angenehm empfinden, wenn eine neue Stufe in der Gliederung vermieden werden kann. Derartige Beispiele könnten an Hand der dieser Arbeit beigegebenen Übersichten beliebig vermehrt werden.

Selbstverständlich bringt es die phylogenetische Anschauungsweise in der Systematik mit sich, daß die einzelnen koordinierten Kategorien oft eine sehr unterschiedliche Anzahl von Arten umfassen und außerdem ihre Organisation eine mitunter verschieden starke weitere Unterteilung notwendig macht. Früher war man nicht selten bestrebt, gleichwertige Gruppen im System möglichst gleich groß zu machen. In einem neuzeitlichen System müssen manchmal wenige Arten einer umfangreichen Zahl von solchen gegenübergestellt werden.

Die Wandlung des Artbegriffes und die verfeinerte Lnterscheidung von Merkmalen innerhalb der Art war der Anlaß für eine häufige Aufstellung von Unterarten, was vor allem auch für zoogeographische Studien bedeutsam wurde. In der systematischen Gliederung drückte sich das so aus, daB die von C. v. Linné eingeführte binäre Nomenklatur, die auch jetzt noch allgemeine Gültigkeit hat, durch eine ternäre Benennung unter Hinzufügen des Namens der Subspecies ergänzt werden kann. Stets aber sind die Unterarten geographisch umrissene Einheiten, die aber in andere Subspecies übergehen können. Das entspricht jedoch dem vielfach verwendeten Begriff der Rasse, welche Bezeichnung ebenso wie die des Rassenkreises, der mit der Art zusammenfällt, nach meiner Ansicht in der Systematik überflüssig ist. Die eine Art spaltet in ihrem Verbreitungsgebiet in mehr oder weniger zablreiche Cnterarten auf, eine andere dagegen nicht.

Bei der Aufstellung eines Systems nach phylogenetischen Gesichtspunkten ist $\mathrm{zu}$ bedenken, daß dieses stets ein künstliches Gebilde sein wird. Schon die Zerlegung der Formenmarmigfaltigkeit der lebenden Natur in einzelne Gruppen ist unnatürlich, so wichtig diese Unterscheidung für die Erfassung durch den menschlichen Geist auch sein mag. Außerdem umfaßt die Lebewelt der Gegenwart nur die Endglieder langer Entwicklungsreihen, und viele von diesen sind dazu vollständig erloschen. Von letzteren aber sind uns zahlreiche unbekannt, teilweise, weil sie sich in Gebieten herausgebildet haben, die bisher einer geologischen Erforschung noch nicht erschlossen wurden; oft aber sind die Organismen einer Untersuchung durch den Menschen ganz entzogen, weil sie sich wenig für eine Fossilisation eigneten und man sie daher in früheren Erdschichten nicht findet. Bekanntermaßen hören die Möglichkeiten für ein Erkennen von Fossilien mit dem Algonkium überhaupt auf; die in den ätesten Schichten nachgewiesene Fauna ist aber bereits weitgehend spezialisiert. Selbst die noch jetzt lebenden Arten kennt man noch nicht vollständig, und ständig werden neue Arten entdeekt. Immerhin wird man die hauptsächlichen Gruppen der lebenden Organismen wahrscheinlich schon erfaßt haben. Trotz aller Schwierigkeiten und Unzulänglichkeiten ist man daher auf Grund unserer derzeitigen Kenntnis doch wohl in der Lage, die rezenten und fossilen Organismen in einem System zusammenzufassen, das die Möglichkeit einer Diskussion phylogenetischer Zusammenhänge erlaubt. 


\section{IV.}

Vor einer systematischen Gliederung der Tierwelt ist zunächst zu klären, welche Lebewesen man als Tiere anspricht. C. v. Linné unterschied bekanntermaßen in der organischen Welt Pflanzen und Tiere. Noch heutigentags wird diese eingebürgerte Einteilung in der Praxis vielfach verwandt, obwohl ihre Unzulänglichkeit hinreichend bekannt ist. Als man nämlich durch die verbesserten optischen Hilfsmittel in der Kenntnis der einzelligen Organismen ungeahnte Fortschritte machte, suchte man auch diese Lebewesen in Pflanzen und Tiere zu scheiden. Man trennte Einzeller mit pflanzlicher von solchen mit tierischer Frnährung, je nachdem die Arten Chlorophyll besaßen oder nicht. Daß sich diese Einteilung von den natürlichen Zusammenhängen zwischen den Organismen weit entfernte, war offensichtlich. Arten, die man nach den morphologischen Verhältnissen unbedenklich in eine Gruppe, selbst in dieselbe Gattung gestellt hätte, müßten so als Pflanze und Tier getrennt werden. Experimentell kann man in dieser Richtung die Scheidung sogar noch weiter treiben, wie C. Ternetz bereits 1912 gezeigt hat ${ }^{1}$ ). Bekanntlich ist bei den in Frage kommenden Einzellern wie bei den Pflanzen das Chlorophyll an Plastiden gebunden, die nachweislich nur aus vorher existierenden Plastiden entstehen. Nach C. Ternetz teilt sich die normal Chlorophyll enthaltende Lichtform von Euglena gracilis Klebs in geeigneter Umwelt (Pepton-Nährlösung) rascher als ihre Plastiden, so daß am Ende nur ein einziger Plastid zwischen 2 Tochter-Euglenen bei einer Zellteilung vergeben werden kann. Ein Exemplar hat daher ohne Plastid auszukommen. Auf diese Weise entsteht eine hyaline Form von Euglena gracilis Klebs, die das Chlorophyll unwiderruflich verloren hat.

Nach dem heutigen Stand der Wissenschaft kommt man den natürlichen Verhältnissen wohl am nächsten, wenn man die Lebewesen nicht mehr wie C. v. Linné in die beiden Reiche der Pflanzen und Tiere einteilt, sondern in 4 verschiedene Reiche. Meine Ansichten stimmen in den hauptsächlichen Zügen mit den Ausführungen überein, die 1948 W. Rothmaler übersichtlich zusammengestellt hat ${ }^{2}$ ).

Das Reich, das in systematischer Hinsicht als primitivstes angesehen werden muß, umfaßt die Bakterien und Cyanophyceen. Es sind das einzellige Organismen, deren Zellinhalt niemals eine Differenzierung in Kern und Cytoplasma aufweist. Man bezeichnet sie zweckmäßig mit dem gebräuchlichen Namen als Reich der Schizophyta. Bei diesen Organismen ist die Entwicklung nicht zu der Ausbildung eines Nucleus fortgeschritten, wie in den Zellen der zu den 3 übrigen Reichen gehörigen Lebewesen, in welchem Kern die Desoxvribonucleinsäure (Thymonucleinsäure) in ganz bestimmter Form lokalisiert ist. Die Schizophyten haben aber andere Ausprägungen der auch bei ihnen vorhandenen Faktoren eines Desoxyribose-Systems und eines Ribonucleinsäure-Systems. Wie G. Piekarski neuerlich zeigen konnte ${ }^{3}$ ), ist bei den Schizophyten das Desoxyribose-System in den Nucleoliden lokalisiert, während das Ribonucleinsäure-System diffus im Cytoplasma verteilt oder isotop mit dem Desoxyribose-System im Karyoid vereinigt sein kann. Schon bei den Schizophyta lassen sich 2 Divisiones unterscheiden: die Bacteria und die Cyanophyceae, die als Abteilung besser Cyanophyta zu bezeichnen sind. Bereits bei den Schizophyten kommen offensichtlich farblose Arten- 
sowohl als primitive wie als abgeleitete Typen vor. Bei ursprünglichen Bakterien ist Bacteriopurpurin und Bacteriochlorophyll zu finden, welch letzterer Stoff dem Chlorophyll a nahestehen dürfte; weitere Farbstoffe kommen vor. Bei den Cyanophyceen ist erstmals eine Differenzierung in farbloses und farbstoffhaltiges Cytoplasma vorbanden.

In ein zweites Reich sind die einzelligen Lebewesen mit Kern zu stellen, bei denen die einzelnen Zellen als Individuen gesondert leben oder aber zu lockeren Verbänden zusammentreten, was sogar so weit gehen kann, daß sich die einzelnen Zellen gegenseitig gestaltlich beeinflussen. Man bezeichnet dieses Regnum als das der Protista. Sie besitzen teils Chlorophyll, teils haben sie solches verloren. In dem von den Protisten ausgebildeten und wesentlich an der Eiweißsynthese beteiligten Nucleus ist das Desoxyribose-System in den Chromosomen Jokalisiert, und das Ribonucleinsäure-System liegt stets isotop mit dem ersteren, vorwiegend aber im Nucleolus. Mit der Ausbildung von Gene tragenden Chromosomen und ihrem Austausch hängt die große Mannigfaltigkeit in der Entstehung verschiedener Mutanten zusammen und mit den möglichen neuen Mutanten, die für irgendeinen Typ der Umwelt besonders geeignet sind, die große Anpassungsfähigkeit und Spezialisierung des Lebens. Im Reich der Protisten bilden sich erstmals Geschlechtsverhältnisse aus, die zu einer Kopulation führen, wobei unter bestimmten Verhältnissen 2 Individuen zu einer Zygote verschmelzen, die bei den Protisten ein verschieden lang dauerndes Ruhestadium darstellt, bis sie durch veränderte AuBenbedingungen zu erneuter Teilung angeregt wird. Bei dem größten Teil der Protisten, von denen hier zunächst die Rede ist, sind die Individuen haploid, die Zygote diploid, mit zygotischer oder gametischer Reduktion. Bei primitiven Formen ist die Kopulation noch eine Hologamie, eine Verschmelzung von 2 Individuen einer Art, die sich nicht von anderen Exemplaren der Species unterscheiden, daher auch einander äuBerlich gleich sind und die als Gameten fungieren. Werden vor der Vereinigung durch besondere Teilungsschritte oder durch multiplen Zerfall Geschlechtsformen gebildet, so spricht man bei ihrer Vereinigung von einer Merogamie. Dabei können die zur Kopulation gelangenden Gameten morphologisch gleich sein (Isogamie) oder mehr oder weniger deutlich schon durch die äuBere Gestalt voneinander abweichen, d.h. männlichen oder weiblichen Charakter haben (Anisogamie). Das Extrem der Anisogamie, eine Differenzierung der sexuellen Formen in einem ähnlichen AusmaB, wie man es bei Ei- und Samenzellen kennt, wird Oogamie benannt. Die Mannigfaltigkeit der Erscheinungsformen bei der Kopulation ist also bei den Protisten so gro $\beta$ wie bei keinem der beiden von ihnen abzuleitenden Reiche der Tiere und Pflanzen. Doch noch eine weitere Möglichkeit im Austausch von Chromosomen kommt bei anderen Protisten vor; der als Konjugation bekannte Vorgang, bei dem sich die beiden Konjuganten aneinanderlegen und nach gewissen cytologischen Vorgängen sogenannte Wanderkerne austauschen; anch bei der Konjugation sind wieder eine Reihe von verschiedenen Erscheinungsformen möglich. Alle diejenigen Protisten, die konjugieren, sind num diploid, im Gegensatz zu den kopulierenden haploiden Arten. Offenbar ist die Konjugation ein sekundärer, ebenfalls innerhalb der Protisten entwickelter Vorgang und vielleicht dureh unterdrückte Merogamie entstanden. 
Auf alle Fälle sind die Verhältnisse bei der geschlechtlichen Fortpflanzung der Protisten infolge der Abweichung der Konjugation von der Kopulation so verschieden, daß es gerechtfertigt ist, danach 2 Divisiones der Protista zu unterscheiden. Man trennt die mit 2 physiologisch ungleichwertigen Kernen im Individuum ausgestatteten Cy toidea (Cilia ta und Suctoria) mit Konjugation von den Cytomorpha mit Kopulation ab, zu welch letzteren neben stark spezialisierten auch die primitivsten Protisten zu rechnen sind. Die Systematik der Cytomorphen bedarf neuzeitlicher Überarbeitung. Eine Erörterung von Einzelheiten hierüber kann nicht Aufgabe der vorliegenden Abhandlung sein. Zu erwähnen ist jedoch, daß die ursprüngliche Form der Cytomorphen, und damit der Protisten, der sogenannte Flagellaten-Typ ist, wie ihn gewisse Vertreter der Mastigophora darstellen; die verschiedensten Gruppen von Cytomorphen bilden diesen Flagellaten-Typ für eine kürzere oder längere Zeit vor der Kopulation ebenfalls aus. Neben anderen Verhältnissen werden wohl vor allem Merkmale der Geißelstruktur eine natürliche Klassifikation der Mastigophoren ermöglichen. Daß die Amoeben, die man lange Zeit als einfache Lebewesen an den Anfang der Protisten gestellt hat, tatsächlich abgeleitete Formen sind, wird gegenwärtig allgemein anerkannt. Für die Rhizopoda dürfte bezüglich der Gameten in systematischer Hinsicht ähnliches gelten wie für die Mastigophora; nur sind bei spezialisierten Formen die äußeren Erscheinungen oft in bestimmten Richtungen abweichend, wie beispielsweise bei den Radiolarien das Vorhandensein eines großen polyploiden Kernes, der sich im Innern des Zentralkapsel in die kleinen Schwärmer aufteilt. Ferner hat es sich wohl durchgesetzt, daß die bewimperten Protisten ohne Konjugation (Opalina-Arten und Verwandte) den Cytomorpha zugerechnet werden, unter denen sie eine besondere, in bestimmter Richtung spezialisierte Gruppe darstellen, aus denen möglicherweise die Cytoidea entsprossen sind. Die von M. M. Metcalf für die Opalina-Verwandtschaft eingeführte Benennung "Protociliata" ${ }^{\text {") }}$ mag daher beibehalten bleiben. $\mathrm{DaB}$ die "Sporozoa" keine natürliche Gruppe darstellen, bedarf keiner erneuten Besprechung. Doch rechne ich nicht allein die zweifellos aus verschiedenen Wurzeln entsprossenen und nur durch die Sporenbildung in $\mathrm{Zu}$ sammenhang mit dem Parasitismus übereinstimmenden Telosporidia und Sarcosporidia, sondern auch die Haplosporidia und Cnidosporidia zu den Cytomorphen. Ich vermag mich der neverlich geäußerten Ansicht nicht anzuschließen, die Cnidosporidia auf Grund ihrer aus mehreren Zellen zusammengesetzten Cnidosporen ganz aus dem Verband der Protisten herauszunehmen und sie den sogenannten Me sozo a zu nähern ${ }^{5}$ ). Zwar handelt es sich bei den Cnidosporidia um eine recht spezialisierte und differenzierte Gruppe; sie aber aus dem Verband der Cytomorphen zu lösen, scheint mir wegen ihrer Entwicklungsgeschichte nicht angängig zu sein.

Die hier gemachten Angaben über die Protisten dürften wohl bereits erkennen lassen, daB es sich nicht durchweg um primitive Lebewesen handelt, wie gelegentlich angenommen wird; sie umfassen vielmehr in vielfacher Hinsicht hochspezialisierte Organismen, deren Gruppen trotz aller Gemeinsamkeiten sich manchmal untereinander recht fern stehen ${ }^{6}$ ). Sicher ist es aber durchaus verfehlt, eine Gruppe als Protozo a innerhalb eines Regnum animsle den Metazoa gegenüberstellen zu wollen, wie das hänfig geschieht. Wenn 
auch Tiere sowohl als Pflanzen zweifellos ihren Trsprung in gewissen Protisten genommen haben, so haben doch die Protisten verschiedene selbständige Entwicklungsrichtungen mit hoher Spezialisation eingeschlagen, die die Aufstellung eines eigenen Regnum rechtfertigen.

Das dritte zu unterscheidende Reich ist das der Pflanzen. So stark die höheren Pflanzen auch von den Protisten abweichen, so ist es doch schwierig, eine Grenze zwischen ihnen und den primitiven Pflanzen zu ziehen. Es kann nicht Aufgabe dieser Abhandlung sein, zu untersuchen, zwischen welchen Formen der stets eine künstliche Maßnahme darstellende Schnitt zweckmäßig zu führen ist. W. Rothmaler geht sogar so weit, noch die Thallophyten den Protisten eingliedern zu wollen ${ }^{3}$ ), was wohl keine allgemeine Zustimmung finden dürfte. Von den Protisten haben die Pflanzen das Vorhandensein von Chlorophyll geerbt, und nur wenige Pflanzen entbehren es. In dem Reich der Pflanzen wie in dem der Tiere erreicht mit ihren spezialisierten Formen die Entwicklung der Organismen je ein von uns als Höhepunkt angesehenes Stadium, die Pflanzen mit autotropher, die Tiere mit heterotropher Lebensweise.

Das Reich der Tiere umfaßt Lebewesen, die als Grundform auf eine Gastrula aus Zellen mit Kern zurückzuführen sind. Kein Tier besitzt Chlorophyll, es sei denn im Körper besonderer einzelliger Organismen, die sekundär im Innern der Tiere als Symbionten leben. Es ist daher anzunehmen, daß bereits die Vorfahren der Tiere chlorophyllose Protisten gewesen sind. Die ursprüngliche Gastrula geht bei sämtlichen Tieren aus einem Blastula-Stadium hervor, indem durch Einstülpung sich 2 Körperschichten (sogenannte Keimblätter) bilden: das Ektoderm und das Entoderm. Durch diese Gastrulation entsteht ein Innenraum, der Urdarm. Mit Hilfe dieser Bildung wird der Organismus in die Lage versetzt, in ihr die Nahrung leichter auszunutzen; die Zellen des Entoderms werden zunehmend für diese Aufgabe spezialisiert. Aus dieser einheitlichen Grundform haben sich die so unterschiedlich gestalteten Tiere entwickelt. Man bezeichnet in der Systematik dieses Regnum als das der Metazoa; W. Rothmaler hat für sie den zwar charakteristischen, doch wohl überflüssigen Namen Gastrobionta vorgeschlagen ${ }^{3}$ ).

Nicht selten hat man die Protisten-Gattung Volrox L., bei der verschiedene Individuen zu einer hohlkugelförmigen Kolonie vereinigt sind, mit der vermuteten Vorstufe der Metazoen verglichen. Das ist grundfalsch. Volvox besteht doch aus Zellen mit haploidem Chromosomensatz, was also von den diploiden Zellen der Metazoen durchaus verschieden ist. Man kann den Körper der Metazoen nur mit der diploiden Zygote der Protisten vergleichen. Dieses bei den Protisten zunächst ein Ruhestadium darstellende Gebilde durchläuft bei den Metazoen eine Periode beträchtlicher Aktivität, und es folgt der Entstehung der Zygote ein reges Wachstum von ihr durch Teilung der diploiden Zellen, wobei im allgemeinen jedoch für die spätere Bildung der haploiden Phase eine sogenannte Keimbahn betont wird. Der aus der Zygote entstandene diploide mehrzellige Organismus ist bei den Metazoen im Lebensablauf der Arten in den Vordergrund gerückt und die herrschende Phase geworden. Doch werden auch von diesem Körper haploide Einzelzellen gebildet, die Geschlechtszellen, die ähnlich wie bei der Oogamie gewisser Protisten in Ei- und Samenzellen geschlechtlich stark differenziert sind. Ursprünglich werden diese haploiden Geschlechtsprodukte ins Wasser entlassen, wo sich die Geschlechter 
finden wie bei den Protisten. Erst mit fortschreitender, in diesem Fall als Brutpflege bezeichneter Spezialisierung werden bei verschiedenen Tiergruppen die Geschlechtsprodukte durch die elterlichen vielzelligen diploiden Organismen zunehmend geschützt und ihnen dadurch der Kampf ums Dasein oft wesentlich erleichtert. Also durchläuft mit der geschlechtlichen Fortpflanzung auch das Tier noch eine haploide Phase als Erbteil seiner Protisten-Vorfahren.

V.

Durch Spezialisierung sind im Laufe der Entwicklung zahlreiche Tierarten entstanden, die zu klassifizieren sind, um ihre Mannigfaltigkeit überblicken zu können. C. จ. Linné hat $1758 \mathrm{im}$ ganzen 4236 Arten lebender Tiere benannt, wovon jedoch 2 Volvox-Arten als Protisten abzuziehen sind. Heutigentags kennt man allein aus Deutschland fast zehnmal so viel lebende Tierarten. Seit 1758 sind zahlreiche neue Species von Tieren aufgestellt und beschrieben worden, so daß man jetzt über eine Million lebender Tiere unterscheidet. Dennoch dürften wir schätzungsweise nicht mehr als höchstens die Hälfte der zur Zeit tatsächlich auf der Erde vorkommenden Arten erfaßt haben. Man muß nämlich bedenken, daß viele Länder bisher erst unzureichend zoologisch erforscht sind und daß noch fortlaufend zahlreiche neue Arten beschrieben werden, allerdings in der Mehrzahl kleinere, unscheinbare Arten.

Die Verteilung der bekannt gewordenen Arten lebender Tiere auf die verschiedenen höheren Kategorien des hier verwendeten Systems herab bis zu den Kreisen ist in Übersicht 1 vermerkt. Die dort gemachten Zahlenangaben lassen erkennen, daß die gleichwertigen Gruppen oft recht unterschiedliche Mengen von Arten umfassen. Ergänzend ist vielleicht darauf hinzuweisen, da $B$ die Klasse der Insekten, deren Artbestand in der Übersicht im Kladus Arthropoda enthalten ist, im ganzen ungefähr 750000 lebende Species umfaBt; das sind annähernd fast drei Viertel der lebenden Fauna, womit die Insekten in der Gegenwart die artenreichste Tierklasse sind. Von den unterschiedenen Insekten-Ordnungen, die über 50000 Arten enthalten, sind die Käfer (Coleop tera) mit etwa 240000 Arten die gröBte; dann folgen die Schmetterlinge (Lepidoptera) mit etwa 105000, die Hautflügler (Hy menoptera) mit etwa 65000 und die $Z$ weiflügler (Diptera) mit etwa 60000 Arten.

Von allgemeinerem Interesse dürtte auch die Artenverteilung innerhalb des Kreises der Wirbeltiere (Vertebrata) sein, für die ein Bestand von etwa 60000 rezenten Species anzunehmen ist. In der Gegenwart ist die Klasse der Vögel (Aves) mit etwa 28000 bekannten Arten die artenreichste. Ihr folgt die Klasse der Fische (Pisces) mit wohl etwas über 20000 Arten. Die übrigen in der gegenwärtigen Fauna vertretenen 4 Klassen haben sämtlich einen wesentlich geringeren Artbestand. Von der Klasse der Kriechtiere (Reptilia), die im Mesozoikum ihre Blütezeit hatte, gibt es nur noch ungefähr 5500 lebende Arten. Nächst der Klasse der Kieferlosen (Agnathi) sind in der Fauna der Gegenwart die Säugetiere (Mammalia) mit etwa 2500 Species die artenärmste Klasse innerhalb der Wirbeltiere.

In Zusammenhang mit den langen Zeitspannen, die die Entwicklung der Tierwelt auf der Erde durchlaufen hat, ist anzunehmen, daß die Zahl der ausgestorbenen Arten eine weit größere ist als die der rezenten. Je stärker nämlich eine Art spezialisiert ist, desto gröBer sind für sie die Gefahren, daB 
sie bei einer Änderung der Umwelt den Anforderungen des Lebens nicht mehr gewachsen ist. Neben solchen erloschenen Arten gibt es andere Typen, die sich im Verlauf geologischer Zeiten durch Mutation so erheblich geändert haben, daß ihre Nachkommen systematisch als besondere Species oder sogar als Angehörige neuer Gruppen gewertet werden müssen. Die einzelnen Tierformen und ihre Arten haben ein recht unterschiedliches geologisches Durchschnittsalter; neben Typen, die bereits in recht frühe Zeiten zurückreichen und sich kaum geändert haben, hat es sicher in allen geologischen Perioden auffallend kurzlebige Gruppen und Arten gegeben. Man hat also mit zunehmenden Zeiten mit einer vermehrten Änderung im Artbestand der Fauna zu rechnen. Dabei läßt sich an Hand fossil gut bekannter Gruppen hinreichend deutlich erkennen, daß die Entwicklungsgesehwindigkeit der Tandtiere infolge der größeren Möglichkeiten in der Ausbildung und im Wechsel einzelner Biotope im allgemeinen rascher zu sein pflegt als bei den im Meer lebenden Tieren. Aus den paläontologischen Untersuchungen geht klar hervor, daB auch bezüglich der größeren systematischen Einheiten die Tierwelt in den einzelnen Erdperioden ganz anders zusammengesetzt war. Aus diesen Gedankengängen heraus mag es also verständlich sein, daß es im Verlauf der vergangenen geologischen Zeiten eine recht erhebliche Menge von nicht mehr existierenden Tierarten gegeben haben muß.

Tatsächlich erreicht aber die Zahl der bisher bekannt gewordenen fossilen Species nur annähernd die Hälfte der lebenden. Diese offensichtliche Lückenhaftigkeit hängt zweifellos in erheblichem AusmaB mit der verschiedenen Erhaltungsfähigkeit der Tiere zusammen. Arten mit versteinerungsfähigen Hartteilen sind bei der Fossilisation begünstigt. Es ist sicher nicht Ausdruck einer beherrschenden Artenzahl in der Zusammensetzung der Fauna früherer Zeiten, wenn die Mollusken mit ihren leicht versteinernden Schalen ungefähr die Hälfte aller bekannten fossilen Tierarten ausmachen. $\mathrm{Zu}$ bedenken ist ferner, daß auch die Häufigkeit von Individuen einer Art und das Vorkommen an bestimmten Biotopen Einfluß auf die Erhaltung und Finbettung als Fossil hat. Da also die Erfassung der ausgestorbenen Tierwelt an bestimmte Voraussetzungen gebunden ist, erscheint es anch nur bedingt möglich, die Zusammensetzung der fossilen Fauna mit derjenigen der rezenten zahlenmäßig zu vergleichen. Deshalb habe ich auch für die fossilen Tierarten keine Zahlen in meiner Übersicht I denjenigen für die rezenten Arten hinzugerechnet. Trotzdem können innerhalb gewisser Tiergruppen Vergleichszahlen zwischen den fossilen Arten und den lebenden aufschluBreich sein. Wenn man beispielsweise von den Brachiopoda mit ihren allendings leicht versteinernden Schalenklappen ungefähr 2600 Arten in recht mannigfaltigen Formen kennt, in der Gegenwart dagegen nur etwa 260 Arten vorkommen, so muB daraus geschlossen werden, daB die Blütezeit dieser Klasse in früheren Erdperioden gelegen hat und sie jetzt im Rückgang begriffen ist. Auch bei anderen Gruppen kann man entsprechende Beobachtungen anstellen.

Bei dem hohen Alter der Tierwelt sollte man eigentlich vermuten, daB mit der Zeit mancher Stamm erloschen ist. Fs spricht für die große Zähigkeit des Lebens, daB man jedoch keinerlei Fossilien kennt, die nicht in die für die lebende Fauna aufgestellten 19 Kreise (Kladus) einzureihen wären. Erst ausgestorbene Klassen von Tieren kennt man. Unter den 80 Klassen, die von 
mir in den dieser Arbeit beigegebenen Übersichten unterschieden werden, befinden sich 13, die ausgestorben sind und die offenbar keine Vertreter mehr in der lebenden Fauna haben. Unter ihnen scheint es mir nur bei den innerhalb der Hohltiere (Coelenterata) aufgestellten Klassen der Graptolithida und der Conularida noch der Nachforschung zu bedürfen, ob sie nicht doch möglicherweise mit lebenden Formen in einer Klasse vereinigt werden können. vielleicht abgetrennt als Unterklassen, und zwar die Graptolithiden mit den Hydrozoa, sowie die Conulariden mit den Scyphozoa. Weitere 13 Einheiten fossiler Tiere werden in meiner Aufstellung als besondere Unterklassen solchen Klassen angegliedert, die sonst noch in der lebenden Fauna vertreten sind. Von den von mir unterschiedenen 401 Ordnungen sind 107 erloschen, also etwa ein Viertel. Daß mit dieser Zahl die Ordnungen ausgestorbener Tiere in Wirklichkeit noch nicht restlos erfaßt sein werden, ist mit Sicherheit anzunehmen, vor allem wenn man bedenkt, wie wenig sich manche Tiere für eine Fossilisation eignen und wie verhältnismäßig klein die Zahl der bekannten fossilen Arten gegenüber den rezenten ist. Je mehr man in den systematischen Kategorien nach unten fortschreitet, bis zu den Arten und Unterarten, desto zahlreicher werden dann die erloschenen Einheiten sein.

VI.

Die große Wichtigkeit auch der fossilen Tiere für die zoologische Systematik macht eine enge Zusammenarbeit von Zoologen und Paläontologen erforderlich. In dieser Beziehung bleibt noch manches zu tun übrig. Zwar hat jeder Paläontologe sich während seiner Ausbildung einmal mit Zoologie beschäftigt; doch pflegen seine Kenntnisse der rezenten Fauna nicht immer mit der zoologischen Forschung Sehritt zu halten. Bedauerlicherweise aber haben sich zahlreiche Zoologen nie mit Paläontologie befaßt. Und doch ist eine ersprießliche Arbeit auf gewissen zoologischen Teilgebieten, wie beispielsweise in der Zoogeographie, ohne gründliche paläontologische und geologische Vorbildung gar nicht möglich. Auch eine systematische Bearbeitung der lebenden Arten mancher Tiergruppen kann ohne Berücksichtigung der fossilen Verwandten nicht durchgeführt werden, oder sie wird doch lückenhaft bleiben. DaB den etwa 260 lebenden Brachiopoden-Arten die zehnfache Zahl formenreicher fossiler Arten gegenübersteht, wurde bereits erwähnt. Es erscheint mir untragbar, diese von zoologischer Seite nicht beachten zu wollen. Von der Klasse der Reptilien hat man in der Gegenwart eigentlich nur noch Trümmer im Vergleich mit der Reichhaltigkeit an Formen bei den Sauriern im Mesozoikum. Es wäre vermessen, diese Klasse allein nach den lebenden Species, die sämtlich nur 4 Ordnungen angehören, abschließend beurteilen zu wollen, denn in ihr sind außer diesen 4 Ordnungen noch weitere 14 ausgestorbene rertreten, teilweise sogar mit mehreren Unterordnungen. Die Reihe von Beispielen läßt sich beliebig fortsetzen.

Bei der biologischen Erforschung der Arten hat der Zoologe größere Möglichkeiten als der Paläontologe, denn der Bearbeiter der rezenten Fauna hat den gesamten, oft noch lebenden Tierkörper vor sich, kann seine Anatomie und bäufig den Entwicklungsablauf der Individuen untersuchen und mit ihnen experimentieren. Der Paläontologe ist nicht selten nur auf die versteinerten Hartteile einer Art angewiesen, und allein unter günstigen Ver- 
hältnissen lassen die Fossilien Körperumrisse und weitere Einzelheiten erkennen; da $B$ das ganze Tier, wie im Bernstein, erhalten bleibt, ist Ausnahme. Wenn eine fossile Art nicht mehr lebend vorkommt, was meistens der Fall sein wird, sind biologische Feststellungen über sie nicht immer ohne weiteres zu machen. Trotzdem können gelegentlich bemerkenswerte Tatsachen an den Fossilien erkannt werden, so etwa Einzelheiten über den Mageninhalt der Tiere, Embryonen im Mutterleib lebendgebärender Arten, bei den Ichthyosauriern beispielsweise sogar Anhaltspunkte über den Geburtsakt. Minutiöse und sinnvolle Forschung an den Fossilien hat in der Paläontologie manch erstaunliches Ergebnis gezeitigt. Doch in gewissen Fragen wird sich der Paläontologe weitgehend nach dem Zoologen richten müssen, wenn letzterer nämlich exaktere Anhaltspunkte für ihre Lösung beibringen kann; in der Frage der Aufstellung höherer Kategorien bei der Klassifikation des Tierreichs ist das sicher der Fall.

VII.

Für die Grundlagen einer möglichst natürlichen systematischen Gliederung der Tiere ist die Tatsache von erheblicher Bedeutung, daß jedes Individuum im Lauf seines Lebens, mehr oder minder deutlich erkennbar, nochmals seine Stammesgeschichte durchläuft. Nachdem bereits Parallelen zwischen Entwicklungszuständen von Tieren und Endstadien anderer Arten erkannt worden waren, hat $\mathbf{E}$. Ha e ckel 1866 diese Erscheinungen in seinem ,biogenetischen Grundgesetz" formuliert. Nach ihm ist also die Ontogenese eine kurze Wiederholung der Phylogenese; auch ist die Phylogenese die Ursache der Ontogenese. Doch vermögen sich nicht nur die Endglieder einer Art durch Mutation weiterzuentwickeln; auch die gesamten Entwicklungsphasen der Species können mutativ abgeändert werden, mitunter einen vollständig veränderten Charakter erhalten und dadurch für bestimmte Biotope geeignet werden. So sind die Larvenformen vielfach sekundär an die verschiedensten Lebensbedingungen angepaßt und oft durch Ausbildung besonderer Larvenorgane erheblich verändert. In Zusammenhang mit der Brutpflege treten nicht selten beträchtliche Abweichungen von der ursprünglichen Ontogenese auf. Häufig sind Abkürzungen in den Entwieklungszuständen. Auch die veränderten Bedingungen des Embryonallebens rufen vielfach starke morphologische Sonderausbildungen und Embryonalorgane verschiedenster Art sekundär hervor. So wird also das Bild einer Wiederholung der von den Vorfahren durchlaufenen Stammesgeschichte in der Ontogenie nicht selten erheblich verwischt und teilweise unkenntlich gemacht. Diejenigen Stadien, die sich in der ontogenetischen Entwioklung einer Art auf ihre Stammformen beziehen, hat man als palingenetische Züge bezeichnet. Dagegen werden als cänogenetisch diejenigen Merkmale unterschieden, durch die die Stammesgeschichte in verschiedenem AusmaB abgeändert worden ist.

Beispiele als Beweis des biogenetischen Grundgesetzes sind in der einschlägigen Literatur zahlreich angegeben. So ist als Wiederholung der Stammesgeschichte sicher die auffälige Erscheinung zu werten, $\mathrm{daB}$ bei den landbewohnenden Wirbeltieren, die doch keine Kiemen mehr haben, im Embryonalstadium noch Kiemenspilten auftreten und zwar in einer Gestalt, die unverkennbar an die entsprechenden Bildungen primitiver Fische erinnern. 
Wenn ferner aus dem Ei eines Leberegels (Fasciola hepatic a L.) und anderer Saugwürmer (Trematoda) eine wasserbewohnende Larve, das Miracidium, kriecht, das den Strudelwürmern (Turbellaria) gleicht, so ist das ohne Zweifel ein Ausdruck dafür, daß die Trematoden von gewissen Turbellarien abzuleiten sind und im Verlauf ihrer phylogenetischen Entwicklung durch Spezialisation zu einer besonderen parasitischen Lebensweise geführt wurden. Die zu den Manteltieren (Tunicata) gehörigen festsitzenden Seescheiden (Ascidiacea) von sackartiger Gestalt machen nach ihrer Organisation den Eindruck recht einfach gebauter Tiere. Doch haben sie ein bewegliches, hoch spezialisiertes Larvenstadium von zweifellos ursprünglichem Charakter, das mit einer Chorda dorsalis ausgestattet ist. Deshalb geht man nicht fehl, die Ascidien systematisch den Chordaten zuzurechnen; die adulten Tiere sind zweifellos also erst sekundär primitiv, wahrscheinlich in Zusammenhang mit ihrer seßhaften Lebensweise.

Cänogenetische Veränderungen an den ursprünglichen Entwicklungsstufen sind bereits an der Gastrula festzustellen. Der ursprüngliche Gastrulationsmodus ist offensichtlich die Entodermbildung durch Einstülpung, die Invagination (Embolie). Sie ist bei den Metazoen auch die häufigste Art der Gastrulabildung und findet sich bei den verschiedensten Tierstämmen. Eine gewisse Veränderung kommt sehon dadurch zustande, daß an der Blastula die Stelle der späteren Einbuchtung vielfach aus etwas größeren Zellen besteht. Wenn die Zellen der vegetativen Zone besonders gro $B$ und dotterreich sind, so wird offenbar aus mechanischen Gründen eine Invagination unmöglich; es findet dann eine Überwachsung der großen Zellen, des späteren Entoderms, durch die sich vermehrenden kleinen Ectodermzellen statt (Epibolie). Unabhängig voneinander sind derartige Erscheinungen verschiedentlich entstanden, so beispielsweise besonders charakteristisch bei Rippenquallen (Ctenophora), bei Rädertieren (Rotatoria), auch bei zahlreichen Gliederwürmern (Annelida). Eine Reihe auffälliger Abweichungen von der normalen Invagination hat sich vor allem bei den Nesseltieren (Cnidaria) herausgebildet, wenn auch unabhängig von ihnen einige ähnliche Erscheinungen bei Vertretern anderer Tiergruppen aufgetreten sind. So findet bei vielen Hydrozoen und einigen Scyphozoen keine Einstülpung statt; vielmehr entsteht dort die Anlage des Entoderms dureh polare Einwucherung (Planula-Larve). Konrergente Verhältnisse kommen bei der Bryozoen-Gattung Flustrella Gray und einigen Crustaceen vor (wenigzellige, polare Einwucherung). Bei zahlreichen Nesseltieren entsteht gar das Entoderm durch multipolare Einwanderung in der Weise, daß an versehiedenen Stellen der Blastula einzelne Zellen nach innen gelangen und sich zu einem Entoderm vereinigen. Von der multipolaren Einwanderung abzuleiten sind verschiedene Formen einer Delamination der Keimblätter. Bei der Blastula-Delamination, die bei Hydrozoen vorkommt, deutlich vor allem bei den Rüsselquallen (Geryoniidae), wird das Entoderm dadurch gebildet, daß die Zellen der Blastula sich parallel zur Oberfläche teilen, wodurch eine innere Lage von Zellen, das Entoderm, entsteht, das, an das Ectoderm angelegt, einen Hohlraum umschließt, der sich später nach außen öffnet. Bei der Morula-Delamination, die unabhängig voneinander bei verschiedenen Gruppen von Nesseltieren entstanden ist, gelangen schon während der Furchung durch parallele Teilungen der Furchungszellen 
Zellen in die Tiefe, so daß der Innenraum vollständig ausgefüllt wird und sich kein Blastocöl bildet (Morula); die Sonderung der Keimblätter geschieht durch Differenzierung der äußeren Zellschicht als Ectoderm. Es erfolgt also die Verlagerung von Zellen ins Innere des Keims zunehmend in frühere Entwicklungsstadien.

Doch bei noch weiter zurückliegenden Stufen in der Entwicklung der Tiere machen sich offenbar cänogenetische Züge bemerkbar, bis zu der Furchung des Keimes. Es besteht kein $Z$ weifel mehr darüber, daß die radiäre Furchung die ursprüngliche Art der Entwicklung ist. Andere Furchungstypen, wie vor allem der auffällige Spiraltypus, aber auch die disymmetrische und die bilateralsymmetrische Furchung, dürften cänogenetische Erscheinungen sein. Auf sie wird noch eingegangen werden müssen.

Für die Klassifikation der Tiere nach phylogenetischen Gesichtspunkten können neben palingenetischen auch cänogenetische Merkmale von Bedeutung sein. Cänogenetische Besonderheiten sind mitunter sogar wichtige systematische Kriterien, wenn sie frühzeitig entstanden sind und sich dann als charakteristisches Merkmal durch ganze Reihen verwandter Tiere hindurch wiederfinden, auch wenn diese sonst stark divergieren. So ist beispielsweise die Bildung einer Trochophora-Larve, die palingenetische mit cānogenetischen Zügen vereinigt, ein wichtiges Anzeichen für die Zusammengehörigkeit der Arten, in deren Entwicklungsablauf diese Larvenform vertreten ist.

Weiterhin hat der Systematiker zu bedenken, daB Arten Merkmale, die sie im Verlauf ihrer Phylogenie verloren haben, nicht mehr in der ursprüng. lichen Form auszubilden vermögen, so weitgehend auch durch Mutation Neubildungen entstehen und selbst bei phylogenetisch sich fernstehenden Arten konvergente Bildungen hervorgerufen werden können. So kann beispielsweise eine von Wassertieren mit Kiemen abstammende landbewohnende Art, die keine Kiemen mehr besitzt, durch Mutation erneut mit anderen Kiemenbildungen ausgestattet werden, durch die sie in der Lage ist, zur aquatilen Lebensweise zurückzukehren; die Kiemen der Vorfahren jedoch kann sie niemals zurückgewinnen. So muß der Systematiker bemüht sein; konvergente Bildungen richtig zu beurteilen. Das gilt auch für die Eingliederung mancher einfach gebauter Tiere, die nicht immer primitiv zu sein brauchen, sondern vielfach sekundär in ihrer Organisation vereinfacht sind, wie das unter bestimmten ökologischen Bedingungen, etwa beim Leben als Parasiten, nicht selten zu beobachten ist. In Zusammenhang mit diesen Fragen der Spezialisation innerhalb des Tierreichs ist vielleicht ein Hinweis darauf angebracht. daß mit zunehmender Organisationshöhe das totipotente Zellmaterial in den Metazoen mehr und mehr verlorengeht. Hierauf ist auch zurückzuführen, daß das Regenerationsvermögen der Tiere mit der Spezialisierung abnimmt. Es ist eine bekannte Tatsache, daB bei zerschnittenen Exemplaren eines Süßwasserpolypen (z.B. Hydra) oder eines Strudelwurmes (z.B. Planaria) die einzelnen Teilstücke sich wieder zu vollständigen Tieren ergänzen. Bei systematisch höherstehenden Gruppen ist diese Fähigkeit weit geringer. Bemerkenswert ist, daß innerhalb der Wirbeltiere die Amphibien außer Schwänzen noch Extremitāten ersetzen können, die Reptilien nur Schwänze, die Vögel Teile des Kieferknochens und des Hornschnabels, während die Säugetiere nur Wnnden zu schließen vermögen. Mit dem Regenerationsvermögen eng verbunden ist die Fähigkeit gewisser Tiere zur ungeschlechtlichen Fortpflanzung. 
VIII.

Bei einer Überprüfung früher Entwicklungsstufen der Tiere im Hinblick auf ihre Verwertung als systematisches Merkmal ist es auffällig, daß die nach der Gastrulation sich festsetzenden Arten sich entweder mit dem Urmund (Blastoporus) oder mit dem apicalen $\mathrm{Pol}$ anheften. Mit diesem gegensätzlichen Verhalten ist ein weiterer auffälliger Untersehied verknüpft. Die mit dem Urmund festsitzenden Arten haben in ihrem Entoderm stets Zellen mit Kragengeißeln, während. die Geißelzellen der übrigen Tiere immer einfache Geißeln tragen, niemals Kragengeißeln. Dieser Lnterschied in der Begeißelung scheint grundlegend zu sein, denn bereits bei den Protisten kommen beide Geißeltypen vor; die eigenartigen Kragengeißeln kennzeichnen innerhalb der Protisten die Gruppe der Choanoflagellata. Es hat danach den Anschein, als ob das Tierreich zwei verschiedene Wurzeln innerbalb der Protisten hat. Aus diesen beiden Ursprüngen haben sich offenbar Lebewesen soweit entwickelt, daß sie durch Gastrulation zu dem wurden, was wir als Tiere bezeichnen. Dureh die Annahme einer verschiedenen Herkunft ist auch das unterschiedliche Verhalten der Gastrula bei der Festsetzung erklärlich.

Ich bin davon überzeugt, daß somit das Tierreich diphyletischen Ursprungs ist. Daß ich trotzdem beide Gruppen in dem Regnum animale zusammenfasse, ist allein eine Maßnahme der Zweckmäßigkeit. Ich halte mich hierzu berechtigt, weil beide Gruppen der Definition der Metaz oa entsprechen und durch eine scharfe Trennung innerhalb des Tierreichs die bestehende Kluft hinreichend ausgedrückt werden kann. Die beiden Einheiten sollen als je eine Abteilung (Divisio) der Metazoa gelten. Es handelt sich bei den mit dem Urmund sich festsetzenden Arten um die Porifera (Schwämme), während die anderen Tiere als Eumetazoa bezeichnet werden.

Bei der Festsetzung der Schwämme (Porifera) mit dem Urmund wird dieser geschlossen. Bei primitiven Formen dienen zahireiche Poren der Leibeswand zur Einfuhr der Nabrung; am apicalen Pol wird eine Auswurföffnung, das Oseulum, gebildet. Zwischen die beiden ursprünglichen Körperschichten schiebt sich eine vom Ectoderm ausgeschiedene Mesenchymschicht, die der Sitz bei den einzelnen Gruppen oft stark spezialisierter Stützsubstanzen sowie der Geschlechtszellen ist. Im Verlauf der Entwicklung der Schwämme werden die ursprünglich nur den Innenraum auskleidenden Entodermzellen (AsconTyp) in die von außen in den Innenraum hineinführenden Kanäle (Sycon-Typ) oder in besondere Kammern, die Geißelkammern (Leucon-Typ), verlagert. Die Abteilung der Schwämme hat mannigfaltige Formen in mehreren Klassen herrorgebracht; doch haben sie bei weitem nicht die Vielseitigkeit der Eumetazoen erreicht.

IX.

Von den Eumetazoen seien zunächst die als Unterabteilung (Subdivisio) angesehenen Hohltiere (Coelenterata) besprochen, weil sie am meisten noch Anklänge an die Gastrula bewahrt haben. Sie treten in zwei voneinander stark abweichenden Einheiten auf. Zu der einen gehören die. wie die Gastrula radiärsymmetrischen Nesseltiere (Cnidaria). Als ihre Grundform ist der Polyp anzusehen. Infolge des Festsetzens der Gastrula mit dem apicalen Pol treten Sinneszellen vermehrt um die Gastralöffnung anf, wo mit fortschreitender 
Entwicklung Tentakelbildungen verschiedener Art entstehen. Vielleicht hängt hiermit auch zusammen, daß bei der von den festsitzenden Polypen abzuleitenden Form der freischwimmenden Medusen die Reizrezeptoren ausschließlich um die Mundöffnung und am Schirmrand liegen, niemals aber auf der Schirmoberseite, deren Mitte der Anheftungsstelle des Polypen entspricht. Innerhalb der Gruppe der Cnidarier haben sich 3 Polypenformen entwickelt. Die einfachste Form ist die des Hydroidpolypen, bei dem die Stelle des Urmundes die definitive Mundöffnung bildet und der Gastralraum ein einfacher Sack bleibt (Klasse Hydrozoa). Bei der zweiten Form, dem Scyphopolypen, ist ebenfalls die Stelle des Urmundes die definitive Mundöffnung; der Gastralraum weist jedoch eine Unterteilung durch 4 Gastralwülste (Taeniolen) auf, die je einen von der Mundscheibe aus entstandenen ectodermalen Muskelstrang enthalten (Klasse Scyphozoa). Die letzte Form, der Anthozoenpolyp, ist dadurch charakterisiert, daB der Urmund als Folge der Ausbildung eines ectodermalen Schlundrohres in die Tiefe verlagert ist; der periphere Gastralraum wird durch vorspringende Längsfalten mit entodermaler Muskulatur in eine Anzahl Taschen unterteilt (Klasse Anthozoa). $\mathrm{Zu}$ den ersten beiden Klassen können entsprechende Medusen gehören.

Bei den Cnidariern wird mit zunehmender Differenzierung ein Mesenchym ausgebildet. Bei den Hydrozoa besteht die Mittelschicht nur aus einer zellenlosen gallertartigen Stützlamelle. Bei den Scyphozoa wie bei den Anthozoa ist dagegen ein wohlausgebildetes zelliges Mesenchym vorhanden. Ein auffälliges Charakteristicum für alle Cnidarier ist das Vorhandensein von Nesselkapseln (Cniden), kompliziert gebauten Gebilden, die im Leben der Tiere von großer Wichtigkeit sind.

Die Anthozoen sind als die höchst entwickelten Cnidarier anzusehen. Es ist bemerkenswert, daß sie in ihrem Entwicklungsgang bei der Gastrulabildung noch am meisten palingenetische Züge aufweisen. Dagegen besitzen die Hydrozoen, die in ihren adulten Formen am wenigsten fortgeschritten sind, starke cänogenetische Änderungen in ihrer Gastrulation. Die Urformen der Cnidarier müssen also Tiere gewesen sein, die die Form des Hydroidpolypen als Endstadium hatten, in den Anfängen ibrer Ontogenie jedoch noch solche Verhältnisse zeigten, wie sie bei den Anthozoen teilweise bis heute erhalten sind.

Die andere zu den Hohltieren (Coelenterata) zu rechnende Gruppe sind die Rippenquallen (Ctenophora). Da diese ron den Cnidariern wesentlich versehieden sind, muß man beide als getrennte Phyla der Hohltiere auffassen. Die Rippenquallen fallen sofort dadurch auf, daB sie keine Nesselkapseln besitzen. Daher müssen ihre Vorfahren sich bereits von den Cnidariern getrennt haben, bevor bei diesen Nesselkapseln auftraten. Die Rippenquallen haben sich von der äußeren Gestalt der Gastrula dadurch mehr als die Nesseltiere entfernt, da sie disymmetrisch geworden sind. Es handelt sich mit wenigen Ausnahmen um freischwimmende Tiere, die zu ihrer Fortbewegung in 8 Reihen angeordnete Flimmerplatten entwickelt haben; diese früher als "Rippen" bezeichneten Organe haben ihnen den Namen gegeben. Da wahrscheinlich die Rippenquallen von freischwimmenden Gastrulaformen, die sich niemals festgesetzt haben, abzuleiten sind, ist es erklärlich, daB im Gegensatz zu den Verhältnissen bei den Cnidariern bei ihnen ein apicaler Sinnespol sich entwickeln konnte. 


\section{X.}

Eine kleine Gruppe parasitisch lebender Tiere, die man meist als ,Planuloidea" oder "Mesozoa" bezeichnet, wurde früher häufig als durch ihre parasitische Lebensweise zurückgebildete Coelenteraten angesehen. Das kann jedoch nicht zutreffen, weil diese ovoiden oder langgestreckten Lebewesen mit einer Planula-Larve der Cnidarier wohl kaum in Verbindung gebracht werden können. Ihre Organisation erinnert vielmehr an eine Morula, weshalb auch die Gruppe durch M. Hartmann als Moruloidea bezeichnet worden ist, welcher Name von mir übernommen wird. Zweifellos handelt es sich um recht primitive Organismen, bei denen eine Sonderung in Ectoderm und Entoderm noch nicht scharf durchgeführt ist, obwohl wichtige Stadien der Tiere zweischichtig sind; offenbar hat man es mit einer primitiven Delamination zu tun. Mit dieser noch unvollständigen Trennung eines Entoderms vom Ectoderm hängt es wohl zusammen, daß die Bildung von Keimzellen zwar meist von den Innenzellen erfolgt, manchmal aber auch von den Außenzellen, also noch nicht auf ein bestimmtes Keimblatt spezialisiert ist. Außerdem ist sicher ein sehr ursprüngliches Merkmal der Moruloidea, daß bei diesen Tieren eine ungeschlechtliche Fortpflanzung durch eine einzige Körperzelle erfolgen kann (Cytogonie), was bei keiner anderen Metazoengruppe der Fall ist; es sind die einzelnen Zellen also noch hochgradig totipotent. Diese Besonderheiten lassen die Aufstellung einer eigenen Unterabteilung der Eumetazoen gerechtfertigt erscheinen. Da die besprochenen Verhältnisse die Moruloidea gegenüber den Coelenteraten als primitivere Gruppe erscheinen lassen, stelle ich sie an den Anfang der Eumetazoa. Ich halte es nicht für notwendig, sie ganz aus dem Verband der Eumetazoen herauszunehmen, weil sie offenbar doch mit ihnen verwandt sind.

Trotz dieser primitiven Züge haben die Moruloidea sich weitgehend spezialisiert und sind sogar in zwei verschiedene Ordnungen zu gliedern. Sie haben einen Generationswechsel ausgebildet, und manche ihrer Eigentümlichkeiten stehen mit ihrer parasitischen Lebensweise in Zusammenhang. Gewisse Stadien von ihnen systematisch als rückgebildete Formen mit den Saugwürmern (Trematoda) in Verbindung zu bringen, erscheint ebenso ungerechtfertigt wie eine Eingliederung in die Hohltiere.

\section{XI.}

Fine dritte Unterabteilung der Eumetazoa sind die Bilateraltiere (Bilateria). Nach meiner Ansicht sind sie wahrscheinlich so entstanden, daB radiär gebaute Eumetazoen, vermutlich in der Gestalt primitiver Vorlänfer der Coelenteraten, sich streckten, vielleicht weil sie in einem weichen Medium dadurch Halt gewannen. Wenn solche Tiere auf festen Untergrund gelangten, sanken sie nicht mit dem aboralen Ende in den Boden, kippten vielmehr um $90^{\circ}$. Sie lagen dann also auf der Seite. Damit ist wohl allmählich eine gewisse Abflachung verbunden gewesen, vor allem, wenn die Individuen sich fortzubewegen versuchten; es bildete sich eine Unter- und eine Oberseite, sowie rechts und links, vorn und hinten. Es entstand dadurch ein bilateraler Wurmtyp. Zur Unterabteilung der Bilateria gehören daher alle Tiere, bei denen auf das Gastrula-Stadium stets ein bilaterales folgt. Fine Weiterentwicklung 
kann entweder die bilaterale Symmetrie beibehalten oder aber auf das bilaterale Stadium ein asymmetrisches oder wieder ein radiäres folgen lassen; selbst ein mehrfacher Wechsel ist möglich.

Durch die Verlängerung der Körperachse wird zwangsläufig auch der Gastralraum verlängert, was wahrscheinlich im Hinblick auf die eine Körperöffnung zu Schwierigkeiten führte. Da das apicale Körperende nicht am Boden festsaß, war dort die Möglichkeit eines Durchbruches des Gastralraumes gegeben. Auch bei den Coelenteraten kommen bei manchen Arten zusätzliche Verbindungen des Gastralraumes mit der Außenwelt vor und zwar bei recht spezialisierten Anthozoen. Bei den in Betracht kommenden Arten haben die zusätzlichen Öffnungen zweifellos in der Hauptsache Bedeutung in Zusammenhang mit dem vielfach unterteilten Gastralraum, wenn auch andere Funktionen hinzukommen können. Es kommen öffnungen an den Spitzen der Tentakeln vor, an der Innenfläche der Randtentakel, am unteren Drittel der Seitenwand (Cincliden, aus denen die mit Nesselkapseln ausgestatteten Acontien als Verteidigungswaffen hervorgeschnellt werden können), sowie ein Porus am aboralen Ende. Bei diesen spezialisierten Coelenteraten war die Organisation schon weitgehend in bestimmter Richtung festgelegt. Bei den primitiven Bilateraltieren war dagegen wahrscheinlich eine sehr viel größere Plastizität vorhanden. Da nun am vorderen wie am hinteren Ende des bilateralen Organismus eine Öffnung vorhanden war, konnte der Verdauungsweg in beiden Richtungen verlaufen, wobei zu bedenken ist, daß die ursprüngliche Öffnung des Gastralraumes doch gleichzeitig Mund und After war. Die Bilateria entwickelten nun zwei verschiedene Gruppen, je nachdem der Urmund zum definitiven Mund und die zusätzliche Öffnung zum After wurde (Protostomia) oder aber umgekehrt (Deuterostomia). Diese Gruppen werden als Phyla innerhalb der Bilateria einander gegenübergestellt. Bei den Protost omia erfährt die Längsachse des Körpers am Vorderende nach der Ventralseite eine Knickung, wodurch der der Nahrungsaufnahme dienende Mund in verschiedenem AusmaB zur Bauchseite verlagert wird. Bei den Deuterostomia bleibt die Achse erhalten, weil die Mundöffnung an der Ventralseite des Vorderrandes neu entsteht. An der Wurzel der versehiedenen Unterabteilungen beider Phyla, mindestens bis zum Kladus, stehen stets Formen, die noch die Wurmgestalt haben. Solche Tiere sind also in verschiedenen systematischen Einheiten zu finden; der äußere Wurmtyp bedingt noch nicht eine systematische Zusammengehörigkeit, weshalb eine Gruppe Vermes nicht vertretbar ist.

Am Anfang der Protostomia stehen wohl die Scolecida, die meist als "Niedere Würmer" bezeichnet werden. Ich möchte sie in Anbetracht ihrer teilweise doch erheblichen Spezialisierung lieber "Urwürmer" benennen. Als ersten Kladus des Subphylum Scolecid a werden meist die Plattwürmer (Plathelminthes) genannt. Sie sind aber sicher nicht die ursprüngliche Form der Protostomier, von denen die übrigen abzuleiten sind. Diese Anordnung am Anfang der Finheit hängt allein mit der linearen Aufzählung der einzelnen Kategorien zusammen; die Plattwürmer sind nämlich diejenigen Tiere, die sich wohl am frühesten vom gemeinsamen Stamm der Protostomier gelöst und eigene Wege der Entwicklung beschritten haben. Wie schon der Name sagt, sind die Plattwürmer stark abgeflacht. Durch Bildung von Darm-

17 Wissenschaftl. Abhandi. IV, 1952 
verzweigungen und Blindsäcken in den Körper hinein konnte der durch starke Mesenchymlagen verdickte Körper in seinem Stoffwechsel besser versorgt werden. Der After verlor als Gegenpol des Mundes seine Bedeutung. Er machte einen Funktionswechsel durch und wurde zum Ausführgang der Bursa ${ }^{7}$ ); der Darm wurde blind geschlossen. Nur bei wenigen Arten ist ein sekundärer After neu gebildet worden, so unter den Turbellarien bei der antarktischen Lept oteredra maculata Hallez und wenigen weiteren zu den Polycladida gehörigen Arten, bei denen der Hauptdarm an seinem Hinterende nach außen mündet; ferner besitzen unter den Trematoden eine Anzahl Digenea einen Darm mit hinterer Öffnung. Bekanntlich sind die Bandwürmer durch ihre parasitische Lebensweise darmlos geworden.

Neben den Plathelminthes.sind unter den Urwürmern mit After zweifellos die Schnurwürmer (Nemertini) frühzeitig vom übrigen Stamm abgezweigt. Das drückt sich darin aus, daß die Larven von beiden Kladus einander ähnlich sind und dem Typ angehören, der als Protrochula bezeichnet wird.

Der Kladus der Urwürmer, der in seinen ursprünglichen Formen dem Bauplan der höheren Protostomier am nächsten kommen dürfte, ist der der Schlauchwürmer (Aschelm inthes). Es ist dabei hauptsächlich an die Klassen der Gastrotrichen und Rotatorien zu denken. Es haben nun alle übrigen Subphyla der Protostomier, die Kranzfühler (Tentaculata), die Weichtiere (Mollusca) und die Gliedertiere (Articulata), soweit sie ihre Entwicklung nicht weitgehend cänogenetisch verändert haben, die als Trochophora-Larve bezeichnete Larvenform, die früher im Bauplan mit den Rädertieren (Rotatoria) identifiziert wurde. Zwar hat P. de Beauchamp bei seinen eingehenden Untersuchungen über die sehr verschiedenen Typen des Räderorgans der Rotatorien überzeugend nachgewiesen, daß ihm der Wimperapparat der sogenannten Trochophora-Larve nicht entspricht ${ }^{8}$ ). Doch zeigt diese immerhin auch sonst soviel Anklänge an den Typ der Rotatorien, daß die Wurzel der Aschelminthen der der Subphyla mit Trochophora-Larve nicht allzu weit entfernt sein dürfte. Dagegen ist unter den Aschelminthen vor allem die Klasse der Fadenwürmer (Nem atoda) eine hochspezialisierte Gruppe mit Sonderentwicklungen. Die erwähnten 3 Subphyla der Protostomier mit Trochophora-Larve haben untereinander wohl keinerlei Beziehungen; sie haben sich vielmehr unabhängig voneinander aus primitiven Scoleciden abgezweigt. Sie spalten im Lauf ihrer Phylogenie in mannigfaltige Gruppen auf, am stärksten wohl die Gliedertiere (Articulata), bei denen drei recht verschiedene Kladus zu unterscheiden sind. Der Kladus der Gliederfüßer erreicht in der Klasse der Insekten die artenreichste Tiergruppe der Gegenwart. Einzelheiten über die Systematik der Protostomier sind aus den beigefügten Ubersichten zu ersehen.

Die Deuterostomia, bei denen der Urmund zum endgültigen After wird, gliedern sich wohl bald nach ihrer Entstehung in 3 Subphyla. Von ihnen haben die Homalopterygia (Gleichflosser) nur wenige Arten hervorgebracht. Die rein marinen Dreihöhlentiere (Coelomopora) haben in den Stachelhäutern (Echinodermata) eine formen- und artenreiche Gruppe. Der bedeutsamste und artenreichste Stamm der Deuterostomia sind aber die Chordata, zu dem neben anderen die Wirbeltiere (Vertebrata) gehören. Algemein ist bei den Bilateria zu beobachten, daB bei ihnen zumehmend 
mesodermale Bildungen an Bedeutung gewinnen, indem nämlich Muskulatur, Bindegewebe, GefäBe, Exkretionsorgane und andere in dem Mesoderm ihren Ursprung haben. Während bei den Coelenteraten allein eine mesenchymatische Schicht zwischen Ectoderm und Entoderm vorhanden ist, bilden sich im Verlauf der Spezialisierung bei den Bilateria Mesepithelsäcke nebst Mesenchym aus. Bei der Mesodermbildung, die durch Einwucherung oder Faltung erfolgen kann, entstehen paarige Höhlungen (Coelome). Deswegen werden die Bilateria oft als ,Coelom ata" bezeichnet. Ich kann mich dem jedoch nicht anschließen, weil das ausschlaggebende, charakteristische Merkmal dieser Tiere das auf die Gastrulation folgende bilaterale Stadium ist. Außerdem haben die Plathelminthen noch keinerlei Coelombildungen; zu dem Gastrovascularsystem sind bei ihnen gegenüber den Coelenteraten nur ein Exkretionssystem (Protonephridialsystem) und Genitalräume hinzugekommen. Auch bei den übrigen Scoleciden finden sich nur Anfänge von Coelombildungen. Erst kei den abgeleiteten Typen sowohl der Protostomier wie der Deuterostomier erlangen Coelombildungen größere Ausmaße.

Diese hier vertretene Klassifikation der Metazoen erfährt dadurch eine weitere Stütze, daß sie mit den Verhältnissen bei der Keimfurchung weitgehend in Einklang zu bringen ist. Bei dem Phylum Cnidaria ist allein der ursprüngliche radiäre Furchungstyp vertreten. Die Arten des spezialisierten Phylum Ctenophora entwickeln aus ihm den disymmetrischen Furchungstyp. Bei den primitiveren Bilateria muß der radiäre Furchungstyp als Erbteil vorhanden gewesen sein. Er ist bei den Deuterostomia erhalten geblieben, bis er bei den Chordata sich zum bilateralen Furchungstyp nur unbedeutend abgewandelt hat. Ziemlich nahe der Wurzel der Protostomia muß aus der radiären Furchung die Spiralfurchung hervorgegangen sein. Dieser charakteristische Furchungstyp findet sich bei allen lebenden Grundformen der Protostomier. Auch die Plathelminthen zeigen in der Keimentwicklung eine Spiralfurchung. Es ist das ein Zeichen dafür, daB sie echte Protostomier sind und nicht etwa als afterlose Stufen der Bilateria vor Protostomiern und Deuterostomiern angesehen werden können, denn sonst müßten sie eine Radiärfurchung haben, da die Deuterostomier noch eine solche zeigen. Die Spiralfurchung ist bei den Protostomiern in den Endgliedern verschiedener Kladus abgeändert oder aufgegeben worden, so bei den Nematoden unter den Aschelminthen, bei den Cephalopoden unter den Mollusken, den Tardigraden und den meisten Arthropoden, vor allem den Insekten, die durch eine superficielle Furchung das ursprüngliche Bild stark verāndert haben.

Bei dem scharfen Schnitt zwischen den Protostomia und den Deuterostomia, der hinreichend durch auffällige Merkmale belegt ist, erscheint es nicht richtig, neben diesen noch eine dritte vermittelnde Gruppe unterscheiden zu wollen. Man hat in ihr die Chaetognatha, Tentaculata, Branchiotremata und Echinodermata vereinigen wollen. Es handelt sich dabei um grundverschiedene Tierformen, sowohl um Protostomier als Deuterostomier, solche mit Radiärfurchung und solche mit Spiralfurchung, die Tentaculaten auch mit dem Typ der Trochophora-Larve, die den anderen fehlt. Eine solche Gruppe ist durchaus unnatürlich, wie wohl aus meinen Ausführungen ersichtlich ist. Fine zwischen Protostomia und Denteros tomia vermittelnde Form ist nur so denkbar, daB innerhalb einer Art, bei der doch zunächșt der 
Urmund als Mund und After fungiert, bei der Öffnung des entgegengesetzten Darmendes der Nahrungsstrom durch den Darmtractus sowohl in der einen wie in der entgegengesetzten Richtung geleitet werden konnte. Durch Spezialisierung auf die eine oder die andere Richtung sind dann Protostomier und Deuterostomier entstanden. Ob eine solche Mittelform, deren Erscheinen bereits in vorkambrische Zeit zurückzu verlegen wäre, überhaupt je existiert hat, sei dahingestellt.

Übersicht 1

Gliederung des Tierreichs in seine einzelnen Stämme

Regnum: Metazoa (Tiere) (etwa 1017700 lebende Arten)

A. Divisio: Porifera $\ldots \ldots \ldots \ldots \ldots \ldots \ldots \ldots \ldots \ldots \ldots \ldots \ldots \ldots \ldots \ldots \ldots \ldots$ (etwa 4500$)$

lebende Arten

a) Phylum et Kladus: Spongiaria (Schwämme).......... (etwa 4500)

B. Divisio: Eumetazoa ....................... (etwa 1013200)

A'. Subdivisio: Moruloidea (Morulatiere)............ (etwa 22)

a) Phylum et Kladus: Moruloidea .................. (etwa 22)

B'. Subdivisio: Coelenterata (Hohltiere)............... (etwa 9000)

a) Phylum et Kladus: Cnidaria (Nesseltiere)............ (etwa 8850)

b) Phylum et Kladus: Ctenophora (Rippenquallen) ......... (etwa 125)

C'. Subdivisio: Bilateria (Bilateraltiere) ............ (etwa 1004150$)$

a) Phylum: Protostomia ..................... (etwa 937900)

a') Subphylum: Scolecida (Urwürmer) ............. (etwa 13350)

Kladus: Plathelminthes (Plattwïrmer) .......... (etwa 5300)

Kladus: Nemertini (Schnurwürmer) ............ (etwa 700)

Kladus: Aschelminthes (Schlauchwürmer) ....... (etwa 7300)

Kladus: Kamptozoa (Kelchwürmer) ${ }^{9}$ ) ............ (etwa 40)

b') Subphylum et Kladus: Tentaculata (Kranzfühler) . . (etwa 3350)

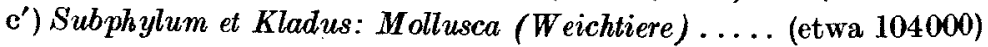

d') Subphylum: Articulata (Gliedertiere) .......... (etwa 817200)

Kladus: Annelida (Gliederwïrmer) ............. (etwa 7020)

Kladus: Tardigrada (Bärtierchen $\left.)^{10}\right) \ldots \ldots \ldots \ldots$ (etwa 180)

Kladus: Arthropoda (Gliederfüßer) ........... (etwa 810000)

b) Phylum: Deuterostomia .................... (etwa 66250)

a') Subphylum: Coelomopora (Dreihöhlentiere) ......... (etwa 4565)

Kladus: Branchiotremata (Kragentiere)........... (etwa 65)

Kladus: Echinodermata (Stachelhäuter) ........... (etwa 4500)

b') Subphylum: Homalopterygia (Gleichflosser) ........... (etwa 30)

Kladus: Chaetognatha (Borstenkiefer) .............. (etwa 30)

$\left.\mathrm{e}^{\prime}\right)$ Subphylum: Chordata (Chordatiere) ............ (etwa 61615)

Kladus: Acrania (Schädellose) .................... (etwa 15)

Kladus: Tunicata (Manteltiere) ............... (etwa 1600)

Kladus: Vertebrata (Wirbeltiere) ............ (etwa 60000) 


\section{Gliederung des Kladus: Spongiaria (Schwämme)}

I. Classis: Calcispongia (Kalkschwämme)

1. Ordo: Asconosa

2. Ordo: Syconosa

$\dagger$ †I. Classis: Archaeocyatha

†1. Ordo: Archaeocyatha

III. Classis: Silicispongia (Kieselschwämme)

I'. Subclassis: Triaxonia (Glassehwämme)

1. Ordo: Hexasterophora

2. Ordo: Amphidiscophora

II'. Subclassis: Tetraxonia (Strahlenschwämme)

1. Ordo: Homosclerophora

2. Ordo: Sigmatophora

3. Ordo: Astrophora

4. Ordo: Desmophora

5. Ordo: Astromonaxonellina

IV. Classis: Cornacuspongia (Nelzfaserschwämme)

1. Ordo: Protorhabdina

2. Ordo: Poikilorhabdina

3. Ordo: Phthinorhabdina

4. Ordo: Aporhabdina

V. Classis: Dendrocerata (Baumfaserschuämme)

1. Ordo: Dendrocerata

Utbersicht 3

Gliederung des Kladus: Moruloidea (Morulatiere)

I. Classis: Moruloidea

1. Ordo: Orthonectida

2. Ordo: Rhombozoa

thersicht 4

\section{Gliederung des Kladus: Cridaria (Nesueltiere)}

I. Classis: Hydrozoa

1. Ordo: Hydroida

1'. Subordo: Athecata

2'. Subordo: Thecata

2. Ordo: Trachylina

1'. Subordo: Trachymedusae

2'. Subordo: Narcomedusae 
3. Ordo: Siphonophora (Staatsquallen) 1'. Subordo: Calycophora 2'. Subordo: Physophora

†4. Ordo: Stromatoporoidea ${ }^{11}$ )

†5. Ordo: Labechioidea ${ }^{11}$ )

†6. Ordo: Sphaeractinioidea ${ }^{11}$ )

†II. Classis: Graptolithida $\left.{ }^{12}\right)$

†1. Ordo: Dendroidea

$\uparrow 2$. Ordo: Graptoloidea $\dagger 1^{\prime}$. Subordo: Axonolipa $\nmid 2$. Subordo: Axonophora

†III. Classis: Conularida

†1. Ordo: Conularida ${ }^{13}$ )

IV. Classis: Scyphozoa

1. Ordo: Lucernarida

2. Ordo: Charybdeida

3. Ordo: Peromedusida

4. Ordo: Discomedusida 1'. Subordo: Semaeostomeae

2'. Subordo: Rhizostomeae

V. Classis: Anthozoa

$\dagger I^{\prime}$. Subclassis: Tetracorallia $\dagger$ 1. Ordo: Tetracorallia

$\dagger I^{\prime}$. Subclassis: Heterocorallia

$\dagger$ 1. Ordo: Heterocorallia

†III'. Subclassis: Trichocorallia

†1. Ordo: Trichocorallia

IV'. Subclassis: Octocorallia

1. Ordo: Stolonifera

2. Ordo: Telestacea

3. Ordo: Alcyonaria

4. Ordo: Grorgonaria l'. Subordo: Scleraronia 2'. Subordo: Holaxonia

5. Ordo: Coenothecalia

6. Ordo: Pennatularia

$V^{\prime}$. Subclassis: Hexacorallia

1. Ordo: Ptychodactiaria

2. Ordo: Actiniaria (Seerosen)

1'. Subordo: Protanthea

2'. Subordo: Endocoelanthea

3'. Subordo: Nynanthea 
Die Stämme des Tierreichs in ihrer systematischen Gliederung

3. Ordo: Zoantharia (Krustenanemonen)

4. Ordo: Madreporaria (Steinkorallen)

I'. Subordo: Astrocoeniida

2'. Subordo: Fungiida

3'. Subordo: Faviida

4'. Subordo: Caryophylliida

5'. Subordo: Dendrophylliida

VI'. Subclassis: Antipatharia (Dörnohenkorallen)

1. Ordo: Antipatharia

VII'. Subclassis: Ceriantharia (Zylinderrosen)

1. Ordo: Ceriantharia

Übersicht 5

Gliederung des Kladus: Ctenophora (Rippenquallen)

I. Classis: Micropharyngea

1. Ordo: Cydippidea

2. Ordo: Tjalfiellidea

3. Ordo: Cestidea

4. Ordo: Bolinopsidea

5. Ordo: Ctenoplanidea

II. Classis: Macropharyngea

1. Ordo: Beroidea (Melonenquallen)

Ubersicht 6

Gliederung des Kladus: Plathelminthes (Plattwïmer)

I. Classis: Turbellaria (Strudelwïrmer)

1. Ordo: Macrostomida

2. Ordo: Catenulida

3. Ordo: Acoela ${ }^{14}$ )

4. Ordo: Rhabdocoela

I'. Subordo: Dalyellioidea

2'. Subordo: Temnocephalida

3'. Subordo: Typhoplanoidea

4'. Subordo: Kalyptorhynchia

5. Ordo: Alloeocoela

1'. Subordo: Archoophora

2'. Subordo: Lecithoepitheliata

3'. Subordo: Cumulata

4'. Subordo: Seriata ${ }^{15}$ )

6. Ordo: Polycladida 
II. Classis: Trematoda (Sauguürmer)

$I^{\prime}$. Subclassis: Monogenea

1. Ordo: Monopisthocotylea

2. Ordo: Polyopisthocotylea

II'. Subclassis: Aspidogastrea

1. Ordo: Aspidogastrea

III'. Subclassis: Digenea

1. Ordo: Gasterostoma

2. Ordo: Prosostomata

III. Classis: Cestoidea (Bandwürmer)

I'. Subclassis: Cestodaria

1. Ordo: Amphilinidea

2. Ordo: Gyrocotylidea

II'. Subclassis: Cestoda

1. Ordo: Tetraphyllidea

2. Ordo: Diphyllidea

3. Ordo: Tetrarhynchidea

4. Ordo: Bothriocephalidea

5. Ordo: Cyclophyllidea

Gliederung des Kladus: Nemertini (Schnurwürmer)

I. Classis: Nemertini (Schnurwürmer)

I'. Subclassis: Anopla

1. Ordo: Palaeonemertini

2. Ordo: Heteronemertini

II'. Subclassis: Enopla

1. Ordo: Hoplonemertini

1'. Subordo: Polystilifera

2'. Subordo: Monostilifera

2. Ordo: Bdellonemertini

Ubersicht 8

Gliederung des Kladus: Aschelminthes (Schlanchwümmer)

I. Classis: Gastrotricha (Bauchhärlinge)

1. Ordo: Macrodasyoidea

2. Ordo: Chaetonotidea

II. Classis: Rotatoria (Rüdertierchen)

1. Ordo: Seisonidea

2. Ordo: Bdelloidea 
Die Stämme des Tierreichs in ihrer systematischen Gliederung

3. Ordo: Monogononta

1'. Subordo: Ploima

2'. Subordo: Flosculariacea

3'. Subordo: Collothecacea

III. Classis: Kinorhyncha (Hakenrïßler)

1. Ordo: Gyclorhaga

2. Ordo: Conchorhaga

3. Ordo: Homalorhaga

IV. Classis: Acanthocephala (Kratzer)

I'. Subclassis: Eoacan thocephala

1. Ordo: Gyracanthocephala

2. Ordo: Neoacanthocephala

II'. Subclassis: Metacanthocephala

1. Ordo: Palaeacanthocephala

2. Ordo: Archiacanthocephala

V. Classis: Nematomorpha (Saitenwürmer)

1. Ordo: Nectonematoidea

2. Ordo: Gordioidea

VI. Classis: Nematodes (Fadenüurmer) ${ }^{16}$ )

I'. Subclassis: Phasmidia

1. Ordo: Rhabditida

l'. Subordo: Rhabditina

2'. Subordo: Tylenchina

3'. Subordo: Strongylina

4'. Subordo: Ascaridina

2. Ordo: Spirurida

1'. Subordo: Camallanina

2'. Subordo: Spirurina

II'. Subclassis: Aphasmidia

1. Ordo: Chromadorida

1'. Subordo: Monhysterina

2'. Subordo: Chromadorina

3'. Subordo: Desmoscoleina

2. Ordo: Enoplida

1'. Subordo: Enoplina

2'. Subordo: Dorylaimina

3'. Subordo: Dioctophymina

Ubersicht 9

Gliederung des Kladus: Kamptozon (Kelehwürmex)

I. Classis: Kamptozoa (Kelchwürmer)

1. Ordo: Pedicellinida 


\section{Gliederung des Kladus: Tentaculata (Kranyfühler)}

I. Classis: Phoronidea (Hufeisenwürmer)

1. Ordo: Phoronidea

II. Classis: Bryozoa (Moostierchen)

I'. Subclassis: Lophopoda (Armwirbler)

1. Ordo: Lophopoda

II'. Subclassis: Stelmatopoda (Kreiswirbler)

1. Ordo: Stenolaemata

1'. Subordo: Cyclostomata

$\lceil 2$. Subordo: Treptostomata

2. Ordo: Gymnolaemata

11'. Subordo: Cryptostomata

2'. Subordo: Cheilostomata

3'. Subordo: Ctenostomata

III. Classis: Brachiopoda (Armfüßer)

I'. Subclassis: Ecardines (Schloßlose Armfüßer)

1. Ordo: Atremata

$\dagger 1^{\prime}$. Subordo: Rustellacea

$2^{\prime}$. Subordo: Lingulacea

$\nmid 3^{\prime}$. Subordo: Obolacea

$\dagger 4^{\prime}$. Subordo: Trimerellacea

$\left\lceil 5^{\prime}\right.$. Subordo: Kutorginacea

2. Ordo: Neotremata

1'. Subordo: Craniacea

$\dagger 2$. Subordo: Siphonotretacea

$\nmid 3^{\prime}$. Subordo: Acrotretacea

4'. Subordo: Discinacea

II'. Subclassis: Testicardines (Schalenschloßarmfüßer)

1. Ordo: Protremata

+1 '. Subordo: Orthacea

2'. Subordo: Strophomenacea

2. Ordo: Telotremata

$\dagger 1^{\prime}$. Subordo: Pentameracea

2'. Subordo: Rhynchonellacea

$\dagger 3^{\prime}$. Subordo: Spiriferacea

4. Subordo: Terebratulacea 


\section{Gliederung des Kladus: Mollusca (Weichtiere)}

a) Suhkladus: Amphineura

I. Classis: Solenoyastres (Wurmmollusken)

1. Ordo: Chaetodermatoidea

2. Ordo: Neomenioidea

II. Classis: Placophora (Käferschnecken)

1. Ordo: Lepidopleurida

2. Ordo: Chitonida

\section{ß) Subkladus: Conchifera}

I. Classis: Gastropoda (Schnecken) ${ }^{17}$ )

$\dagger I^{\prime}$. Subclassis: Amphigastropoda (Urschnecken) ${ }^{18}$ )

$\dagger$ 1. Ordo: Tryblidiacea

†2. Ordo: Bellerophontacea

II'. Subclassis: Streptoneura (Gekreuztnervige) ${ }^{19}$ )

1. Ordo: Diotocardia

2. Ordo: Monotocardia 1'. Subordo: Taenioglossa

2'. Subordo: Stenoglossa

III'. Subclassis: Euthyneura (Geradnervige) ${ }^{20}$ )

1. Ordo: Cephalaspidea

2. Ordo: Basommatophora

3. Ordo: Stylommatophora

1'. Subordo: Soleolifera

2'. Subordo: Heterurethra

3'. Subordo: Orthurethra

4'. Subordo: Sigmurethra

4. Ordo: Thecosomata.

5. Ordo: Oncidiace ${ }^{21}$ )

6. Ordo: Aplysiacea

7. Ordo: Gymnosomata

8. Ordo: Acochlidiacea

9. Ordo: Sacoglossa

10. Ordo: Notaspidea

11. Ordo: Nudibranchia

1'. Subordo: Holohepatica

2 '. Subordo: Cladohepatica

3'. Subordo: Rhodopacea

II. Classis: Scaphopoda (Grabfüßer)

1. Ordo: Seaphopoda 
III. Classis: Bivalvia (Muscheln)

1. Ordo: Taxodonta

2. Ordo: Anisomyaria

3. Ordo: Eulamellibranchiata

1'. Subordo: Schizodonta

2'. Subordo: Heterodonta

3'. Subordo: Adapedonta

4'. Subordo: Anomalodesmata

IV. Classis: Cephalopoda (Kopffuißer)

I'. Subclassis: Tetrabranchiata (Vierkiemer)

1. Ordo: Nautiloidea (Nautilusartige)

$\dagger 1^{\prime}$. Subordo: Volborthellacea

†2'. Subordo: Endoceracea

†3'. Subordo: Orthoceracea

4'. Subordo: Nautilacea

†5'. Subordo: Ascoceracea

$+6^{\prime}$. Subordo: Actinoceracea

$\dagger 7^{\prime}$. Subordo: Cyrtoceracea

†2. Ordo: Ammonoidea (Ammoniten)

$\dagger l^{\prime}$. Subordo: Goniatitacea

$\dagger 2$. Subordo: Clymeniacea

†3'. Subordo: Ceratitacea

†4'. Subordo: Ammonitacea

II'. Subclassis: Dibranchiata (Zweikiemer)

1. Ordo: Decabrachia (Zehnarmige, Tintenfische) ${ }^{22}$ )

$\dagger 1^{\prime}$. Subordo: Belemnoidea (Belemniten)

2'. Subordo: Sepioidea

3'. Subordo: Loliginacea

4'. Subordo: Architeuthacea

2. Ordo: Octobrachia (Achtarmige, Kraken) ${ }^{22}$ )

$\dagger 1^{\prime}$. Subordo: Palaeoctobrachia

2'. Subordo: Cirrata

3'. Subordo: Incirrata

Gliederung des Kladus: Annelida (Gliederwürmer)

I. Classis: Polychaeta (Vielborster)

1. Ordo: Errantia

1'. Subordo: Amphinomorpha

2'. Subordo: Nereimorpha

2. Ordo: Sedentaria

1'. Subordo: Spiomorpha

2'. Subordo: Drilomorpha

3'. Subordo: Terebellomorpha

4'. Subordo: Serpulimorpha

3. Ordo: Archiannelida ${ }^{23}$ ) 
II. Classis: Clitellata (Gürtelwürmer)

1. Ordo: Oligochaeta (Wenigborster)

1'. Subordo: Plesiopora

2'. Subordo: Prosopora

3'. Subordo: Opisthopora (Regenwürmer)

2. Ordo: Hirudinea (Egel)

1'. Subordo: Acanthobdellida (Borstenegel)

2'. Subordo: Rhynchobdellida (Rüsselegel)

3'. Subordo: Gnathobdellida (Kieferegel)

4'. Subordo: Pharyngobdellida (Schlundegel)

III. Classis: Echiuroidea (Quappenwïrmer)

1. Ordo: Echiurida

$l^{\prime}$. Subordo: Echiuroinea

2'. Subordo: Xenopneusta

3'. Subordo: Heteromyota

2. Ordo: Saccosomatida

IV. Classis: Sipunculida (Sternwürmer)

1. Ordo: Sipunculida.

V. Classis: Priapulida (Priapuliden $)^{24}$ )

1. Ordo: Priapulida

Gliederung des Kladus: Tardigrada (B̈̈rtierchen)

I. Classis: Tardigrada

1. Ordo: Heterotardigrada

1'. Subordo: Arthrotardigrada

2'. Subordo: Echiniscoidea

2. Ordo: Eutardigrada

Übersicht 14

Gliederung des Kladus: Arthropoda (Gliederfüßer)

a) Subladus: Malacopedn (Weichfüber)

I. Classis: Onychophora ${ }^{25}$ )

†1. Ordo: Protonychophora

2. Ordo: Euonychophora 
ß) Subkladus: Diantennata (Krebsartige) ${ }^{26}$ )

†I. Classis: Trilobita (Dreilapper)

$\dagger$ 1. Ordo: Hypoparia

†2. Ordo: Opisthoparia

+3. Ordo: Proparia

$\dagger$ II. Classis: Cheloniellida (Schildkrötenkrebse) ${ }^{27}$ )

$\dagger$ 1. Ordo: Cheloniellida

III. Classis: Crustacea (Krebse)

I'. Subclassis: Branchiopoda (Kiemenfüßer)

1. Ordo: Anostraca ${ }^{28}$ ) $\dagger 1$ '. Subordo: Lipostraca

2'. Subordo: Euanostraca

2. Ordo: Phyllopoda (Blattfüßer) ${ }^{28}$ )

1'. Subordo: Notostraca

2'. Subordo: Onychura ${ }^{29}$ )

†II'. Subclassis: Marriocarida ${ }^{30}$ )

$\dagger$ 1. Ordo: Marriocarida

$\dagger \mathrm{III}^{\prime}$. Subclassis: Marrellomorpha $\mathrm{a}^{31}$ )

$\dagger$ 1. Ordo: Pygaspida

†2. Ordo: Marrellida

†3. Ordo: Mimetasterida

IV'. Subclassis: Ostracoda (Muschelkrebse)

1. Ordo: Myodocopa

2. Ordo: Podocopa

$V^{\prime}$. Subclassis: Copepoda (Ruderfüßer)

1. Ordo: Mystacocarida

2. Ordo: Eucopepoda

1'. Subordo: Calanoida

$2^{\prime}$. Subordo: Harpacticoida

3'. Subordo: Cyclopoida

4'. Subordo: Notodelphyoida

5'. Subordo: Monstrilloida

6. Subordo: Caligoida

7'. Subordo: Lernaeopodoida

3. Ordo: Branchiura (Karpfenläuse) ${ }^{32}$ )

VI'. Subclassis: Cirripedia (Rankenfüßer)

1. Ordo: Thoracica

$\dagger 1$ '. Subordo: Turrilepadomorpha

2'. Subordo: Lepadomorpha

3 '. Subordo: Verrucomorpha

$4^{\prime}$. Subordo: Balanomorpha

2. Ordo: Acrothoracica

3. Ordo: Ascothoracica

4. Ordo: Apoda

5. Ordo: Rhizocephala (Wurzelkrebse) 
Die Stämme des Tierreichs in ihrer systematischen Gliederung

VII'. Subclassis: Malacostraca (Echte Krebse)

1. Ordo: Phyllocarida ${ }^{33}$ )

$\dagger l^{\prime}$. Subordo: Hymenocarina

$\dagger 2^{\prime}$. Subordo: Ceratiocarina

$\nmid 3$. Subordo: Rhinocarina

4'. Subordo: Nebaliacea

†2. Ordo: Nahecarida

3. Ordo: Syncarida ${ }^{34}$ )

4. Ordo: Peracarida ${ }^{35}$ )

l'. Subordo: Lophogastridea

2'. Subordo: Mysidacea

3'. Subordo: Amphipoda (Flohkrebse)

4'. Subordo: Cumacea

5'. Subordo: Tanaidacea (Scherenasseln)

$6^{\prime}$. Subordo: Isopoda (Asseln)

5. Ordo: Eucarida

1'. Subordo: Euphausiacea

2'. Subordo: Pygocephalomorpha

3'. Subordo: Decapoda (Zehnfüßige Krebse)

6. Ordo: Hoplocarida (Maulfüßer) ${ }^{36}$ )

ү) SubkJadus: Chelicerata (Scherengreifer)

†I. Classis: Arthrocephala

†1. Ordo: Arthrocephala

†II. Classis: Gigantostraca

$\dagger 1$. Ordo: Gigantostraca

III. Classis: Xiphosura

†1. Ordo: Synxiphosura

2. Ordo: Euxiphosura (Pfeilschwänze)

IV. Classis: Pantopoda (Asselspinnen)

†1. Ordo: Palaeopantopoda ${ }^{3 i}$ )

2. Ordo: Eupantopoda

1'. Subordo: Colassendeomorpha

2'. Subordo: Nymphonomorpba

3'. Subordo: Ascorbynchomorpha

4'. Subordo: Pycnogonomorpha

V. Classis: Linguatulida (Zungenwrïmer) ${ }^{33}$ )

1. Ordo: Cephalobaenida

2. Ordo: Porocephalida

VI. Classis: Arachnoidea (Spinnentiere)

$I^{\prime}$. Subclassis: Latigastra

1. Ordo: Scorpionida (Skorpione) 
2. Ordo: Pseudoscorpionida (Afterskorpione)

l'. Subordo: Chthoniinea

2'. Subordo: Neobisinea

3'. Subordo: Cheliferinea

3. Ordo: Opilionidea (Weberknechte)

1'. Subordo: Cyphophthalmi

2'. Subordo: Laniatores

3'. Subordo: Palpatores

†4. Ordo: Phalangiotarbida

5. Ordo: Acarina (Milben)

1'. Subordo: Notostigmata

2'. Subordo: Holothyroidea

3'. Subordo: Parasitiformes

4'. Subordo: Trombidiformes

5'. Subordo: Sarcoptiformes

6'. Subordo: Tetrapodili

†II'. Subclassis: Stethostomata

$\uparrow$ 1. Ordo: Haptopoda

†2. Ordo: Anthracomarti

III'. Subclassis: Soluta

1. Ordo: Trigonotarbi

IV'. Subclassis: Caulogastra

1. Ordo: Palpigradi

2. Ordo: Schizonotida

3. Ordo: Telyphonida

†4. Ordo: Kustarachnida

5. Ordo: Phrynichida

6. Ordo: Arachnida (Echte Spinnen)

1'. Subordo: Mesothelae

2'. Subordo: Orthognatha

3'. Subordo: Labidognatha

7. Ordo: Ricinulei (Blindspinnen)

8. Ordo: Solifugae (Walzenspinnen)

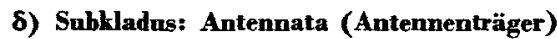

I. Classis: Symphyla (Zwergfüßer)

1. Ordo: Symphyla

II. Classis: Pauropoda (Wenigfüßer)

1. Ordo: Pauropoda

III. Classis: Diplopoda (Doppelfüßer)

$I^{\prime}$. Subelassis: Pselaphognatha (Pinselfüßer)

†1. Ordo: Lophotricha

2. Ordo: Ancyrotricha 
Die Stầmme des Tierreichs in ihrer systematischen Gliederung

II'. Subclassis: Chilognatha (Tausendf üBer)

1. Ordo: Limacomorpha

2. Ordo: Oniscomorpha

3. Ordo: Ascospermophora

4. Ordo: Colobognatha

5. Ordo: Proterospermophora

6. Ordo: Opisthospermophora

IV. Classis: Chilopoda (Hundertfüßer)

I'. Subclassis: Notostigmophora (Rückenatmer)

1. Ordo: Notostigmophora

II'. Subclassis: Pleurostigmophora (Seitenatmer)

1. Ordo: Anamorpha (Steinläufer)

I'. Subordo: Lithobiomorpha

2'. Subordo: Craterostigma

2. Ordo: Epimorpha (Erdläufer)

I'. Subordo: Geophilomorpha

2'. Subordo: Scolopendromorpha

V. Classis: A pterygota (Urinsekten)

1. Ordo: Diplura (Doppelschwänze)

2. Ordo: Thysanura (Borstenschwänze)

3. Ordo: Protura (Beintastler)

4. Ordo: Collembola (Springschwänze)

1'. Subordo: Arthropleona

2'. Subordo: Symphypleona

VI. Classis: Insecta (Insekten.)

$\left\lceil I^{\prime}\right.$. Subclassis: Palaeodictyoptera

$\dagger$ 1. Ordo: Palaeodictyoptera

II'. Subclassis: Ephemeroidea ${ }^{39}$ )

1. Ordo: Ephemerida (Eintagsfliegen)

III'. Subclassis: Libelluloidea

$\dagger$ 1. Ordo: Protodonata (Riesenlibellen)

2. Ordo: Odonata (Libellen)

1'. Subordo: Anisozygoptera

2'. Subordo: Anisoptera

3'. Subordo: Zygoptera

IV'. Subclassis: Perloidea

1. Ordo: Plecoptera (Steinfliegen)

$V^{\prime}$. Subclassis: Embioidea

†1. Ordo: Hadentomoidea

2. Ordo: Embioptera (Embien)

Wiseenschaftl. Abhand1. TV, 1952 
II'. Subclassis: Orthoptera (Geradflügler)

$\dagger$ 1. Ordo: Protorthoptera

2. Ordo: Saltatoria (Heuschrecken)

3. Ordo: Phasmida (Gespenstheuschrecken)

4. Ordo: Dermaptera

1'. Subordo: Forficulinea (Ohrwürmer)

$2^{\prime}$. Subordo: Hemimerinea ${ }^{40}$ )

5. Ordo: Thysanoptera (Blasenfüßer)

VII'. Subclassis: Blattoidea

$\dagger$ 1. Ordo: Protoblattoidea (Urschaben)

2. Ordo: Blattaria (Schaben)

3. Ordo: Mantodea (Fangschrecken)

4. Ordo: Isoptera (Termiten)

5. Ordo: Zoraptera (Bodenläuse)

6. Ordo: Copeognatha (Staubläuse)

7. Ordo: Phthiraptera (Tierläuse)

1'. Subordo: Mallophaga (Federlinge, Pelzfresser)

2'. Subordo: Anoplura (Läuse)

VHII'. Subclassis: Coleopteroidea

†1. Ordo: Protocoleoptera

2. Ordo: Coleoptera (Käfer)

I'. Subordo: Adephaga

2'. Subordo: Polyphaga

3. Ordo: Strepsiptera (Fächerflügler) ${ }^{41}$ )

IX'. Subclassis: Rhynchota (Schnabelkerfe)

$\dagger$ 1. Ordo: Protohemiptera

†2. Ordo: Palaeohemiptera

3. Ordo: Homoptera (Pflanzensauger)

I'. Subordo: Cicadina (Zikaden)

2'. Subordo: Psyllina (Blattflöhe)

3'. Subordo: Aleurodina (Mottenläuse)

4'. Subordo: Aphidina (Blattlāuse)

5'. Subordo: Coecina (Schildläuse)

4. Ordo: Heteroptera (Wanzen)

1'. Subordo: Gymnocerata (Landwanzen)

2'. Subordo: Cryptocerata (Wasserwanzen)

$X^{\prime}$. Subclassis: Hymenopteroidea

11. Ordo: Archaeohymenoptera

†2. Ordo: Palaeohymenoptera

†3. Ordo: Protohymenoptera

4. Ordo: Hymenoptera (Hautflügler)

1'. Subordo: Symphyta (Pflanzenwespen)

2'. Subordo: Terebrantia (Schlupf- und Goldwespen)

3'. Subordo: Aculeata (Stachelwespen) 
XI'. Subclassis: Planipennia

1. Ordo: Megaloptera (Schlammfliegen)

2. Ordo: Raphidiodea (Kamelhalsfliegen)

3. Ordo: Neuroptera (Netzflügler)

XII'. Subclassis: Panorpoidea

$\dagger$ 1. Ordo: Megasecoptera

2. Ordo: Panorpata (Schnabelfliegen)

3. Ordo: Trichoptera (Köcherfliegen)

4. Ordo: Lepidoptera (Schmetterlinge)

1'. Subordo: Jugata

2'. Subordo: Frenata

5. Ordo: Diptera (Zweiflügler)

1'. Subordo: Nematocera (Mücken)

2'. Subordo: Brachycera (Fliegen)

6. Ordo: Aphaniptera (Flöhe)

Gliederung des Kladus: Branchiotremata (Kragentiere)

1. Classis: Enteropneusta (Eichelwürmer)

1. Ordo: Enteropneusta

II. Classis: Pogonophora (Bartträger) ${ }^{42}$ )

1. Ordo: Pogonophora

III. Classis: Pterobranchia (Flügelkiemer)

1. Ordo: Pterobranchia

Übersicht 16

Gliederung des Kladus: Echinodermata (Stachelhäuter)

a) Subkladus: Pelmatozoa (Gestielte Stachelhüuter)

$\dagger$ †. Classis: Cystoidea (Beutelstrahler)

†1. Ordo: Dichoporita

†2. Ordo: Diploporita

$\dagger$ II. Classis: Edrioasteroidea ${ }^{43}$ )

$\dagger$ 1. Ordo: Edrioasteroidea.

†III. Classis: Carpoidea (Blattstrahler)

$\dagger$ 1. Ordo: Carpoidea

†IV. Classis: Blastoidea (Knospenstrahler)

$\dagger$ 1. Ordo: Protoblastoidea

†2. Ordo: Eublastoidea 
V. Classis: Crinoidea (Seelilien)

$\dagger$ 1. Ordo: Camerata

†2. Ordo: Adunata

$\uparrow 3$. Ordo: Inadunata $\dagger 1^{\prime}$. Subordo: Larviformia $\lceil 2$. Subordo: Fistulata

†4. Ordo: Flexibilia $\dagger l^{\prime}$. Subordo: Sagenocrinida $\dagger 2^{\prime}$. Subordo: Taxocrinida

5. Ordo: Pentacrinoidea 1'. Subordo: Bourgueticrinida

2'. Subordo: Pentacrinida 3'. Subordo: Holopida

6. Ordo: Comatulida 1'. Subordo: Oligophreata 2'. Subordo: Macrophreata

ß) Subkladus: Eleutherozoa (Ungestielte Stachelhäuter)

I. Classis: Asteroidea (Seesterne)

1. Ordo: Phanerozonia (Großplattenseesterne)

2. Ordo: Cryptozonia (Kleinplattenseesterne)

$\dagger$ †I. Classis: Auluroidea ${ }^{44}$ )

$\dagger$ 1. Ordo: Auluroidea

III. Classis: Ophiuroidea (Schlangensterne)

$\dagger I^{\prime}$. Subclassis: Aegophiurida

$\dagger 1$. Ordo: Lysophiurida

II'. Subclassis: Myophiurida

$\dagger$ 1. Ordo: Ophiocystiida

†2. Ordo: Aganasterida

3. Ordo: Phrynophiurida

4. Ordo: Laemophiurida

5. Ordo: Gnathophiurida

6. Ordo: Chilophiurida

IV. Classis: Echinoidea (Seeigel)

$\dagger \mathrm{I}^{\prime}$. Subclassis: Palechinoidea

$\dagger$ 1. Ordo: Bothriocidarida

$\dagger$ 2. Ordo: Cystocidarida

†3. Ordo: Perischoechinida $+l^{\prime}$. Subordo: Lepidocentroidea +2 . Subordo: Archaeocidaroidea $\lceil 3$. Subordo: Melonechinoidea $\dagger 4^{\prime}$. Subordo: Tiarechinoidea

II'. Subclassis: Euechinoidea

1. Ordo: Cidaroidea 
Die Stämme des Tierreichs in ihrer systematischen Gliederung

2. Ordo: Centrechinoidea

1'. Subordo: Camarodonta

2'. Subordo: Aulodonta

3'. Subordo: Stirodonta

3. Ordo: Exocycloidea

1'. Subordo: Holectypina

2'. Subordo: Echinoinea

3'. Subordo: Clypeastrina

4'. Subordo: Nucleolitina

$\overline{5}^{\prime}$. Subordo: Cassidulina

$6^{\prime}$. Subordo: Spatangina

V. Classis: Holothurioidea (Seegurken)

1. Ordo: Dendrochirota

2. Ordo: Elasipoda

3. Ordo: Aspidochirota

4. Ordo: Molpadonia

a. Ordo: Paractinopoda

Übersicht 17

Gliederung des Kladns: Chaetognatha (Borstenkiefer)

I. Classis: Sagittoidea (Pfeilwürmer)

1. Ordo: Sagittoidea

Ubersicht 18

Gliederung des Kladus: Acrania (Schädellose)

1. Classis: Leptocardia (Röhrenherzen, Lanzettischchen)

1. Ordo: Leptocardia

Gliederung des Kladus: Tunienta (Manteltiere)

I. Classis: Copelata (Geschwänzte Manteltiere)

1. Ordo: Copelata

II. Classis: Ascidiacea (Seescheiden)

1. Ordo: Aplousobranchiata

2. Ordo: Phlebobranchiata

3. Ordo: Stolidobranchiata

4. Ordo: Aspirieulata

III. Classis: Thaliacea (Salpen)

1. Ordo: Gyclomyaria

2. Ordo: Desmomyaria 
Gliederung des Kladus: Vertebrata (Wirbeltiere)

I. Classis: Agnathi (Kieferlose) ${ }^{45}$ )

1. Ordo: Cyclostomata (Rundmäuler)

1'. Subordo: Hyperoartia

2'. Subordo: Hyperotreta

†2. Ordo: Anaspida

$\uparrow$ 3. Ordo: Heterostraci

†4. Ordo: Osteostraci

†5. Ordo: Thelodonti

†. Ordo: Palaeospondyloidea

†II. Classis: A phetohyoidea (Urfische) ${ }^{46}$ )

$\dagger$ 1. Ordo: Antiarchi

†2. Ordo: Arthrodira $\dagger l^{\prime}$. Subordo: Euarthrodira $\nmid 2^{\prime}$. Subordo: Phyllolepida

$\uparrow$ 3. Ordo: Acanthodi

†. Ordo: Petalichthyida

†5. Ordo: Rhenanida

†6. Ordo: Stegoselachia

III. Classis: Pisces (Fische)

I'. Subclassis: Chondrichthyes (Knorpelfische)

$\dagger$ 1. Ordo: Cladoselachii

†2. Ordo: Pleuracanthodii

3. Ordo: Plagiostomi I'. Subordo: Selachii (Haie)

2'. Subordo: Batoidei (Rochen)

4. Ordo: Holocephali (Seekatzen)

$\left\lceil l^{\prime}\right.$. Subordo: Bradyodonti

2'. Subordo: Chimaerida

II'. Subclassis: Osteichthyes (Knochenfische)

1. Ordo: Crossopterygii (Quastenflosser) ${ }^{ \pm i}$ )

1'. Subordo: Actinistia $\dagger 2$. Subordo: Rhipidistia

2. Ordo: Dipnoi (Lungenfische)

3. Ordo: Chondrostei (Störartige)

$\dagger l^{\prime}$. Subordo: Palaeoniscoidea

2'. Subordo: Polypterini (Flösselhechte)

†3'. Subordo: Belonorhynchoidea

4'. Subordo: Acipenseroidea (Störe)

4. Ordo: Holostei

$\dagger 1^{\prime}$. Subordo: Orthoganoidea

$\dagger 2$. Subordo: Pycnodonti

3'. Subordo: Rhomboganoidea (Kaimanfische) 
4'. Subordo: Cycloganoidea (Kahlhechte)

$\left\lceil 5^{\prime}\right.$. Subordo: Pholidopteroidea

5. Ordo: Teleostei (eigentliche Knochenfische)

+1 '. Subordo: Leptolepiformes

2'. Subordo: Clupeiformes (Heringsfisehe)

3'. Subordo: Ostariophysi (Karpfenähnliche)

4'. Subordo: Esociformes (Hechtartige)

5'. Subordo: Anguilliformes (Aalartige)

6'. Subordo: Symbranchiformes (Kurzschwanzaale)

7'. Subordo: Scombresociformes (Hornhechtartige)

8'. Subordo: Gasterosteiformes (Stichlingsartige)

9'. Subordo: Nothacanthiformes (Dornrückenfische)

10'. Subordo: Mugiliformes (Meeräschenartige)

11'. Subordo: Gadiformes (Dorsehartige)

12'. Subordo: Acanthopterygii (Stachèlflosser)

IV. Classis: Amphibia (Lurche) ${ }^{48}$ )

I'. Subclassis: Lepospondyli

$\dagger$ †. Ordo: Nectridia

2. Ordo: Caudata (Schwanzlurche)

1'. Subordo: Cryptobranchoidea

2'. Subordo: Amblystomoidea

3'. Subordo: Salamandroidea

4'. Subordo: Proteidea

†3. Ordo: Aistopoda

4. Ordo: Gymnophiona (Blindwühlen) ${ }^{49}$ )

†5. Ordo: Microsauria ${ }^{50}$ )

II'. Subclassis: Apsidospondyli ${ }^{51}$ )

†1. Ordo: Ichthyostegalia

†2. Ordo: Labyrinthodonta

†'. Subordo: Embolomeri

+2 '. Subordo: Rhachitomi

$\nmid 3$. Subordo: Stereospondyli

$\nmid 3$. Ordo: Proanura

4. Ordo: Salientia (Frösche)

1'. Subordo: Amphicoela

2'. Subordo: Opisthocoela

3'. Subordo: Anomocoela

4'. Subordo: Procoela

5'. Subordo: Diplasiocoela

V. Classis: Reptilia (Kriechtiere) ${ }^{52}$ )

I'. Subclassis: Anapsida

†1. Ordo: Cotylosauria

+1 . Subordo: Sermouriamorpha ${ }^{53}$ )

+2'. Subordo: Diadectomorpha

$\nmid 3^{\prime}$. Subordo: Procolophonia

$+4^{\prime}$. Subordo: Pareiasauria

†5'. Subordo: Captorhinomorpha

†2. Ordo: Eunotosauria ${ }^{54}$ ) 
3. Ordo: Testudines (Schildkröten)

1'. Subordo: Pleurodira (Halswender)

2'. Subordo: Cryptodira (Halsberger)

3'. Subordo: Cheloniidea (Meeresschildkröten)

4'. Subordo: Trionychoidea (Weichschildkröten)

†I'. Subclassis: Metapsida

$\dagger$ 1. Ordo: Ichthyosauria (Fischechsen) ${ }^{55}$ )

$\dagger l^{\prime}$. Subordo: Latipinnati

$\dagger^{\prime} 2^{\prime}$. Subordo: Longipinnati

fIII'. Subclassis: Synapsida

$\dagger$ 1. Ordo: Pelycosauria ${ }^{56}$ )

$\dagger{ }^{\prime}$. Subordo: Ophiacodontia

$\dagger 2$. Subordo: Sphenacodontia

+3 '. Subordo: Edaphosauria

†2. Ordo: Therapsida ${ }^{57}$ )

$\dagger 1^{\prime}$. Subordo: Dromasauria

$\dagger 2$. Subordo: Deinocephalia

$\uparrow^{\top}$ '. Subordo: Anomodontia

$\nmid 4$. Subordo: Rubidginia

$\dagger 5$. Subordo: Gorgonopsia

t6'. Subordo: Therocephalia

$\left\lceil 7^{\prime}\right.$. Subordo: Bauriamorpha

$\dagger 8$. Subordo: Cynodontia

$\uparrow 9^{\prime}$. Subordo: Ietidosauria

†3. Ordo: Mesosauria

†4. Ordo: Placodontia

†5. Ordo: Sauropterygia

$+1^{\prime}$. Subordo: Nothosauria

+2 . Subordo: Plesiosauria

†6. Ordo: Protorosauria

IV'. Subelassis: Diapsida

†1. Ordo: Thecodontia ${ }^{58}$ )

$\nmid 1$ '. Subordo: Eosuchia

$\left\lceil 2^{\prime}\right.$. Subordo: Psendosuchia

$\lceil 3$ '. Subordo: Parasuchia

2. Ordo: Crocodilia (Krokodile)

$+l^{\prime}$. Subordo: Protosuchia

$\lceil 2$. Subordo: Mesosuchia

3'. Subordo: Ensuchia

†3. Ordo: Saurischia ${ }^{59}$ )

$\dagger 1^{\prime}$. Subordo: Coelurosauria

†2'. Subordo: Pachypodosauria

+4. Ordo: Ornithischia ${ }^{59}$ )

$\dagger 1^{\prime}$. Subordo: Ornithopoda

$\lceil 2$. Subordo: Ponderopods

$\nmid 3$. Subordo: Thyreophora 
†5. Ordo: Pterosauria (Flugsaurier)

$\dagger$ I'. Subordo: Rhamphorhynchoidea

$\uparrow 2^{\prime}$. Subordo: Pterodactyloidea

$V^{\prime}$. Subclassis: Katapsida ${ }^{60}$ )

1. Ordo: Rhynchocephalia (Brückenechsen)

1'. Subordo: Sphenodontoidea

$\dagger 2$. Subordo: Rhynchosauria

$\nmid 3$ '. Subordo: Champsosauroidea

$\dagger$ 2. Ordo: Thalattosauria

3. Ordo: Squamata (Schuppenreptilien)

$\dagger^{\prime}$. Subordo: Prolacertilia

2'. Subordo: Lacertilia (Echsen)

3'. Subordo: Ophidia (Schlangen)

VI. Classis: Aves (Vögel) ${ }^{\mathbf{6}}$ )

$\dagger I$. Subclassis: Archaeornithes (Urvögel)

†1. Ordo: Archaeornithes

II'. Subclassis: Ornithurae (eigentliche Vögel) ${ }^{6 *}$ )

$\dagger I^{\prime \prime}$. Superordo: Odontognatha (Zahnvögel)

$\dagger 1$. Ordo: Hesperornithes

†2. Ordo: Ichthyornithes

II'. Superordo: Ratitae (Flachbrustvögel)

1. Ordo: Crypturi (Steißhühner)

2. Ordo: Apterygiformes

1'. Subordo: Apteryges (Kiwis)

$\nmid 2$. Subordo: Dinornithidea (Moas)

3. Ordo: Casuarii (Kasuarartige)

†4. Ordo: Aepyornithes (Madagaskarstrauße)

5. Ordo: Struthioniformes (Straußartige)

$1^{\prime}$. Subordo: Rheae (Nandus) ${ }^{63}$ )

2'. Subordo: Struthiones (eigentliche StranBe)

III". Superordo: Euornithes (Kielbruströgel)

1. Ordo: Galliformes (Hühnerartige)

1'. Subordo: Opisthocomi (Zigeunerhühner)

2'. Subordo: Galli (Hühnervögel)

2. Ordo: Gruiformes (Kranichartige)

1'. Subordo: Cariamae (Seriemas)

†'2'. Subordo: Phororhaci 4 )

3'. Subordo: Psophiae (Trompetervögel)

4'. Subordo: Grues (Kraniche)

5'. Subordo: Eurypygae (Sonnenrallen)

6'. Subordo: Heliornithes (Binsenhähner)

7'. Subordo: Rhynocheti (Kagus)

8'. Subordo: Otides (Trappen)

9. Subordo: Ralli (Rallen)

10'. Subordo: Mesoenades (Stelenrallen)

11'. Subordo: Turnices (Kampfwechteln) 
$\dagger 3$. Ordo: Diatrymiformes ${ }^{65}$ )

4. Ordo: Charadrïformes (Watvögel und Möwen)

I'. Subordo: Charadrii (Watrögel)

2'. Subordo: Lari (Möven)

3'. Subordo: Alcae (Alke)

5. Ordo: Gaviae (Seetaucher)

6. Ordo: Podicipedes (Lappentaucher)

7. Ordo: Tubinares Sturmvögel)

8. Ordo: Sphènisci (Pinguine)

9. Ordo: Steganopodes (RuderfüBler)

10. Ordo: Gressores (Schreitvögel)

11. Ordo: Phoenicopteri (Flamingos)

12. Ordo: Anseriformes (Gänseartige)

1'. Subordo: Anhimae (Wehrvögel)

2'. Subordo: Anseres (Schwimmvögel)

13. Ordo: Accipitres (Tagraubvögel)

14. Ordo: Columbiformes (Taubenartige)

1'. Subordo: Pterocletes (Flughühner)

2'. Subordo: Columbae (Tauben)

15. Ordo: Cuculiformes (Kuckucksartige)

1'. Subordo: Musophagi (Turakos)

2'. Subordo: Cuculi (Kuckucke)

16. Ordo: Psittaci (Papageien)

17. Ordo: Striges (Eulen)

18. Ordo: Caprimulgi (Ziegenmelker)

19. Ordo: Trogones (Trogons)

20. Ordo: Coraciiformes (Rackenartige)

1'. Subordo: Coraciae (Racken)

2'. Subordo: Halcyones (Eisvögel)

3'. Subordo: Meropes (Bienenfresser)

4'. Subordo: Momoti (Sägeracken)

5'. Subordo: Todi (Todis)

6'. Subordo: Upupae (Hopfartige)

21. Ordo: Colii (Mausvögel)

22. Ordo: Macrochires (Schwirrvögel)

I'. Subordo: Micropodi (Segler)

2'. Subordo: Trochili (Kolibris)

23. Ordo: Piciformes (Spechtartige)

1'. Subordo: Galbuloidea (Glanzvögel)

2'. Subordo: Picoidea (Spechtrögel)

24. Ordo: Passeres (Sperlingsvögel)

1'. Subordo: Eurylaimi (Breitmãuler)

2'. Subordo: Tyranni (Tyrannenartige)

3'. Subordo: Menurae (Leierschwãnze)

4'. Subordo: Oscines (Singrögel) 
Die Stämme des Tierreichs in ihrer systematischen Gliederung

VII. Classis: Mammalia (Säugetiere)

I'. Subclassis: Prototheria (Ursäugetiere)

$\dagger$ 1. Ordo: Multituberculata

2. Ordo: Monotremata (Kloakentiere) ${ }^{66}$ )

†3. Ordo: Pantotheria ${ }^{67}$ )

†4. Ordo: Symmetrodonta

†5. Ordo: Triconodonta

II'. Subclassis: Marsupialia (Beuteltiere)

1. Ordo: Polyprotodontia (Vielvorderzähner)

2. Ordo: Caenolestoidea (Wenigvorderzähner)

3. Ordo: Diprotodontia (Zweivorderzähner)

III'. Subclassis: Placentalia (Plazentasäugetiere)

1. Ordo: Insectivora (Insektenfresser)

1'. Subordo: Menotyphla

2'. Subordo: Lipotyphla

2. Ordo: Dermoptera (Pelzflatterer)

3. Ordo: Chiroptera (Flattertiere)

1'. Subordo: Megachiroptera (Fliegende Hunde)

2'. Subordo: Microchiroptera (Fledermäuse)

4. Ordo: Pholidota (Schuppentiere)

5. Ordo: Xenarthra

$\dagger$ 1'. Subordo: Taeniodonta

†2'. Subordo: Palaeanodonta

3'. Subordo: Hicanodonta (Gürteltiere)

4'. Subordo: Anicanodonta (Ameisenbären, Faultiere, Riesenfaultiere)

†6. Ordo: Tillodontia

7. Ordo: Rodentia (Nagetiere)

1'. Subordo: Duplicidentata (Doppelzähner)

2'. Subordo: Simplieidentata (Einfachzähner)

8. Ordo: Carnivora (Raubtiere) ${ }^{8}$ )

$\dagger 1^{\prime}$. Subordo: Acreodi

$\dagger 2 \%$. Subordo: Pseudocreodi

$\nmid 3$. Subordo: Eucreodi

4'. Subordo: Aeluroidea

5'. Subordo: Arctoidea

9. Ordo: Cetacea (Wale)

†1'. Subordo: Archaeoceti (Urwale)

2'. Subordo: Odontoceti (Zahnwale)

3'. Subordo: Mysticeti (Bartenwale)

10. Ordo: Hyracoidea (Klippschliefer)

$\dagger$ 11. Ordo: Embrithopoda

12. Ordo: Proboscidea (Rüsseltiere)

$\dagger l^{\prime}$. Subordo: Moeritherioidea

2'. Subordo: Elephantoidea

$\dagger^{\prime \prime}$. Subordo: Deinotherioidea

$\dagger 4^{\circ}$. Subordo: Barytherioides 
13. Ordo: Sirenia (Seekühe)

$\dagger$ 14. Ordo: Pyrotheria

$\dagger$ 15. Ordo: Notungulata

$\dagger 1^{\prime}$. Subordo: Notioprogonia

$\lceil 2$. Subordo: Toxodontia

$\uparrow 3$. Subordo: Typotheria

$\left\lceil 4^{\prime}\right.$. Subordo: Hegetotheria

$\dagger$ 16. Ordo: Astrapotheria

$\uparrow$ I'. Subordo: 'Trigonostylopoidea

$\uparrow 2$. Subordo: Astrapotherioidea

17. Ordo: Tubulidentata (Erdferkel)

18. Ordo: Mesaxonia (Unpaarhufer)

$\dagger 1^{\prime}$. Subordo: Condylarthra (Urbuftiere)

$\lceil 2$. Subordo: Litopterna

$3^{\prime}$. Subordo: Perissodactyla (Tapire, Nashörner, Pferde) ${ }^{69}$ )

$\uparrow 4^{\prime}$. Subordo: Ancylopoda

†5'. Subordo: Amblypoda

19. Ordo: Artiodactyla (Paarhufer)

1'. Subordo: Bunodontia (Nilpferde, Schweine)

$\nmid 2$. Subordo: Bunoselenodontia

$\nmid 3^{\prime}$. Subordo: Hypoconifera

4'. Subordo: Ruminantia (Wiederkāuer)

20. Ordo: Prosimiae (Halbaffen)

1'. Subordo: Tarsioidea (Koboldmakis)

2 '. Subordo: Lorisoidea (Loris)

3'. Subordo: Lemuroidea (Lemuren)

4'. Subordo: Chiromyoidea (Fingertiere)

21. Ordo: Platyrhina (Neuweltaffen) ${ }^{70}$ )

22. Ordo: Pithecoidea (Altweltaffen)

1'. Subordo: Cercopithecoidea (Tieraffen)

2 . Subordo: Hylobatoidea (Gibbonartige)

3'. Subordo: Anthropomorpha (Menschenaffen)

\section{Anmerkungen}

1) C.Ternetz: Beiträge zur Morphologie und Physiologie der Euglena gracilis Klebs. Jahrb. wissensch. Botanik. 51. Bd. Leipzig 1912. pag. 435-514. Taf. VI.

$\left.{ }^{2}\right)$ W. Rothmaler: Über das natürliche System der Organismen. Biolog. Zentralblatt. 67. Bd. Leipzig 1948. pag. 242-250.

3) G. Piekarski: Die Zellkernäquivalente der Bakterien. 2. Colloquium Deutsch. Ges. physiol. Chemie 1951 in Mosbach-Baden. GieBen 1951. Fag. $83-101$.

4) M. M. Metcalf: The Opalinid Ciliate Infusorians. Smithsonian Instit. Un. States Nation. Mus. Bulletin 120. Washington 1923.

5) W. Ulrich: Begriff und Einteilung der Protozoen. Moderne Biologie. Festschr. 60. Geburtst. H. Nach tsheim. Berlin 1950. pag. 241-250. W. Clrich: Vorschläge zu einer Revision der Großeinteilung des Tier- 
reiches. Verhandl. Deutsch. Zool. Ges. 1950. Zoolog. Anzeig. 15. Supplementband. Leipzig 1951. pag. 244-271.

$\left.{ }^{6}\right)$ J. R. Baker: The Status of the Protozoa. Nature. Vol. 161. London 1948. pag. 548-551, 587-589.

7) A. Remane: Die Bursa-Darmverbindung und das Problem des Enddarmes der Turbellarien. Zool. Anzeig. Bd. 146. Heft 9-10. Leipzig 1951. pag. 275-291.

8) P. de Beauchamp: Morphologie et variations de l'appareil rotateur dans la série des Rotifères. Arch. Zool. Expér. et Génér. 4. Sér. Tome VI. Paris 1907. pag. 1-19. - P. Marais de Beauchamp: Recherches sur les Rotifères. Les formations tégumentaires et l'appareil digestif. Arch. Zool. Expér. et Génér. 4. Sér. Tome X. Paris 1909. pag. 1-410. PI. I-IX.

9) Die Kelchwürmer (Ka m ptoz oa) erinnern durch ihre bewimperten Tentakel an Moostierchen (Bryozoa), denen sie früher auch eingereiht wurden. Die nähere Untersuchung zeigt jedoch, daß die beiden Gruppen tiefgreifende Unterschiede aufweisen und offenbar nur durch ihre gleichartige Lebensweise als festsitzende Strudler einander äußerlich ähnlich geworden sind. Die von den Tentakeln umschlossene Körperregion ist bei den Kamptozoen die Bauchseite, ihr Tentakelkranz ein praeoraler, wobei also der After ventralwärts gekrümmt innerhalb des T'entakelkranzes liegt. Dagegen wird bei den Bryozoen von den Tentakeln nur der Mund umsäumt; der Tentakelkranz ist ein postoraler, und der After liegt, dorsalwärts gebogen, außerhalb des Tentalkranzes. Die Kamptozoen haben eine Trochophora-Larve, weshalb ihre Wurzel nicht weit von der der primitiven Aschelminthen sein wird. Die Besonderheiten im Körperbau dieser nur aus wenigen Arten bestehenden Gruppe rechtfertigt jedoch die Aufstellung eines besonderen Kladus.

10) Die Bärtierchen (Tardigrada) werden meist den Gliederfüßern (Arthropoda) systematisch eingegliedert, obwohl eigentlich alle typischen Charaktere dieses Kladus fehlen. Aus demselben Grund kann auch die manchmal vorgenommene Einreihung in die Gliederwürmer (Annelida) nicht befriedigen. Ich sehe mich deshalb genötigt, für diese Tierchen innerhalb der Gliedertiere (Articulata) einen besonderen Kladus zu schaffen.

11) Die vom Kambrium bis in die Kreide weitverbreiteten Stroma topor oidea sind wohl den Hydrozoa einzugliedern, innerhalb welcher Klasse man sie wohl am besten in eine besondere Ordnung stellt. Dasselbe gilt für die vom Silur bis zum Karbon vertretenen Labechioidea und die Sphaeractinioidea rom Perm bis in die Kreide.

12) Die als Leitfossilien für das Silur so hervorragend geeigneten Graptolithen kommen auf Schieferplatten dieser Formation so häufig vor, daB man von Graptolithenschiefer spricht. Doch war die systematische Stellung dieser Fossilien lange Zeit zweifelhaft. Die Zoologen neigten meist zu der Annahme, sie den Kragentieren (Branchiotremata) einzugliedern und den Flügelkiemern (Pterobranchia) zu nähern. Doch trifft das wohl nicht $\mathrm{zu}$, und die Graptolithen simd überhaupt keine sessilen bilateralen Tiere. Nach den Tierkolonien mit offenbar oft becherförmigen Theken zu urteilen, handelt es sich eher um Coelenteraten und zwar um stockbildende Polypen, die den Bydrozoa zu nähern sind. Am besten stellt man die 
Graptolithida einstweilen als besondere Klasse neben die Hydrozoa. $\mathrm{Ob}$ sie diesen einzugliedern sind, vielleicht als besondere Unterklasse, bedarf weiterer Untersuchung. Auch erscheint es noch nicht sicher erwiesen, daß diese formenreiche Gruppe phylogenetisch einheitlich ist und alle beschriebenen Formen ihr tatsächlich zuzuzählen sind.

13) Die eigentümlichen Conularien, die vom Kambrium bis in die Trias vertreten sind, müssen offenbar den Scyphoz oa genähert werden. $O b$ die letzteren von Conularien abzuleiten sind, wie vermutet wurde, erscheint möglich, ist jedoch noch nicht erwiesen. Am besten stellt man beide Gruppen als verschiedene Klassen nebeneinander, könnte vielleicht auch die Conularida als Unterklasse den Scyphozoa voranstellen, falls weitere Argumente für ihre vermutete nähere Verwandtschaft beigebracht werden sollten.

14) Die marine Turbellarien von einfacher Organisation umfassende Ordnung Acoela, bei welchen Tieren statt des Darmes eine zentrale verdauende Zellmasse vorhanden ist und deren Pharynx eine einfache Hauteinsenkung ist oder ganz fehlt, ist sicher eine abgeleitete Gruppe und nur sekundär primitiv. Bei den als ursprünglich angesehenen lebenden 'Turbellarien ist der After bereits geschlossen und der Darm sackartig.

$\left.{ }^{15}\right)$ In die Unterordnung Seriata der Alloeocoela werden nach neuzeitlicher Klassifikation auch diejenigen im Süßwasser und auf dem Land vorkommenden Strudelwürmer gerechnet, die man früher als Tricladen bezeichnete und als "Tricladidea" neben die Alloeocoela stellte.

16) Bei der Klassifikation der Fadenwürmer (Nematoda) richte ich mich im allgemeinen nach der Einteilung, wie sie B. G. Chitw ood durchgeführt hat (B. G. Chitwood: A Revised Classification of the Nematoda. Bureau of Animal Industry, Washington, D. C. Washington 1933). Ihm ist auch T. Goodey bei seiner Bearbeitung der Land- und SüBwasser-Nematoden gefolgt (T. Goodey: Soil and Freshwater Nematodes. London and New York 1951). Der dabei angewandten und von B. G. Chitwood und M. B. Chitw ood 1933 vorgeschlagenen Gliederung der Klasse Ne mat oda in die beiden Unterklassen Phasmidia und Aphasmidia (B. G. Chitwood and M. B. Chitwood: The Characters of a Protonematode. Bureau of Animal Industry, Washington, D. C. Washington 1933) ist sicher beizupflichten. Doch ist die Benennung der Unterklassen sehr unglücklich gewählt wegen der thereinstimmung des Wortstammes mit der eingebürgerten Bezeichnung Phasmida für die zu den Orthopteren gehörige Ordnung der Gespenstheuschrecken. Fine Umbenennung der Cnterklassen der Fadenwürmer wird sich wohl kaum umgehen lassen.

17) Die Schnecken (Gastropoda) gruppiert man am natürlichsten nach dem mit der Drehung des Pallialkomplexes zusammenhängenden Verhalten der sogenannten Visceralschlinge des Nervensystems, welche Entwicklung mit dem Vorhandensein anderer charakteristischer Merkmale parallel läuft. Bei der einen Gruppe, der Unterklasse Streptoneura (= Prosobranchia) ist eine auffällige Asymmetrie durch Überkreuzung der beiden Hälften der Visceralschlinge vorhanden (Streptoneurie, Chiastoneurie). Die Cnterklasse umfaBt unter den lebenden Arten zweifellos die ursprünglichsten. Zu einer zweiten Gruppe, der Unterklasse Eu th yne u ra, gehören 
Schnecken, bei denen die Visceralschlinge eine Rückdrehung (Detorsion) aus dem streptoneuren Zustand erfährt. Es sind das ohne Zweifel von streptoneuren Ahnen abgeleitete Formen, was schon daraus folgt, daß die in Zusammenhang mit der Torsion einseitig in Verlust geratenen Organe auch ihnen fehlen.

Während diejenigen lebenden Schneckenarten, die selbst an der Schale keine Rechts- oder Linksdrehung mehr erkennen lassen, in ihren Weichteilen stets asymmetrisch gebaut sind und dadurch ihre Ableitung von asymmetrischen Gruppen verraten, gibt es einige fossile Schneckenarten, die offenbar noch ursprünglich bilateralsymmetrisch sind. Einige von ihnen haben an der Schale noch getrennte, paarig symmetrisch angeordnete Haftmuskeleindrücke, was sicher ein sehr altertümliches Merkmal ist und an die Verhältnisse bei den Placophora erinnert. Diese fossilen Schnecken, die mit ihren schüsselartigen, kegelförmigen oder symmetrisch nach vorn oder hinten spiralen Schalen als primär bilateral angesehen werden, können auch noch keine streptoneure Visceralschlinge gehabt haben. Man muB diese in Betracht kommenden Fossilien in eine besondere, ausgestorbene Unterklasse der Gastropoden stellen, von denen zweifellos die Streptone ura abzuleiten sind. Ich bezeichne sie mit W. Wenz als A m phigastropoda (W. Wenz: Ursprung und frühe Stammesgeschichte der Gastropoden. Arch. Molluskenkunde. Bd. 72. Frankfurt a.M. 1940. pag. 1-10).

Die Aufstellung einer besonderen Unterklasse der "Lungenschnecken (Pulmonata)" innerhalb der Gastropoda hat keinerlei Berechtigung. In ihr hatte man früher diejenigen euthyneuren Schnecken zusammengefaßt, die atmosphärische Luft durch die vascularisierte Decke der Mantelhöhle atmen oder atmen können. Entsprechende Ausbildungen finden sich ebenfalls bei versehiedenen Gruppen der Streptoneura, die man auch nicht als besondere Einheit von den kiemenatmenden Arten trennt. Die Schaffung einer Unterklasse der „Pulmonaten“ läBt die natürlichen Zusammenhänge innerhalb der Eu thyneura nicht erkennen.

18) Die erloschenen bilateralsymmetrischen Amphigastropoda umfassen 2 Ordnungen. Die ursprünglicheren Arten sind die Tryblidiacea, welche Ordnung durch ihre getrennten, paarig symmetrisch angeordneten Haftmuskeleindrücke noch die Abstammung der Gastropoden von Placophorenartigen Vorfahren vermuten läßt. Es ist anzunehmen, daß die schüsselartigen Schalen im allgemeinen den primitiven Arten angehört haben werden und daß durch eine Aufwölbung des Eingeweidesackes Arten mit kegelförmiger Schale entstanden sind. Das sind umgekehrte Verhältnisse wie bei den Streptoneura und Euthyneura, unter denen gerade die flachschaligen Formen die abgeleiteten sind. Die Tryblidiace a treten im Algonkium auf, haben ihre Blütezeit im Silur und erlöschen zu Beginn des Mesozoikums. Zu ihnen sind die Tryblidiidae und Metoptomatidae zu rechnen.

Die 2. Ordnung, die Bellerophontacea, sind wohl aus Tryblidiacea durch symmetrische Einrollung der Schale nach vorn oder hinten entstanden. Hinzu kommt eine mehr oder weniger starke Verschmelzung der Muskeleindrücke. Die Bellerophontacea waren offenbar vorwiegend pelagische Tiere. Sie beginnen im Kambrium und erlöschen in der Trias, 
Hierher gehören die Cyrtolitidae, Sinuitidae, Bucaniidae, Bellerophontidae, Carinaropsidae und Pterothecidae.

19) Die Unterklasse Streptoneura wird meistens in die 3 Ordnungen Archaeogastropoda, Mesogastropoda und Stenoglossa eingeteilt. Sehon der Name "Archaeogastropoda ${ }^{\text {" }}$ ist irreführend, nachdem man jetzt weit altertümlichere Gastropoden kennt. Ich halte die früher vielfach verwandte Benennung der Ordnungen nach der Beschaffenheit des Herzens für richtiger. Danach sind bei den Streptoneuren die Diotocardia mit der ursprünglichen Organisation des Herzens mit Herzkammer und 2 Vorhöfen, sowie die Monotocardia mit einer Herzkammer und nur noch 1 Vorhof zu unterscheiden. Die Diotocardia entsprechen den „Archaeogastropoden". In dieser Ordnung wird die ursprüngliche paarige Anlage mancher Organe (Kiemen, Nephridien) zunehmend durch Reduktion der Organe auf der einen Seite verändert. Die Schale zeigt noch weitgehend Perlmutterstruktur.

Bei den Monotocardia ist die einseitige Ausbildung von Kieme und Nephridium abgeschlossen. Die Schale ist nicht mehr perlmuttrig. Ich unterteile diese Ordnung in 2 Unterordnungen, die den beiden Gruppen der Mesogastropoda und Stenoglossa entsprechen. Nur verwende ich für die „Mesogastropoda“", deren Radula meist taeniogloss ist, den alten Namen Taenioglossa, der auch besser den Gegensatz zu den Stenoglossa ausdrückt.

20) Bei den Euthyneura erfolgt neben der Rückdrehung der Visceralschlinge des Nervensystems unabhängig bei verschiedenen Gruppen gleichzeitig eine Verkürzung der Kommissuren, so daß die Ganglien einander oft genähert sind.

Die primitivste Ordnung der Euthyneuren sind die Cephalaspidea. Bei ursprünglichen Formen dieser Gruppe, den Actaeonidae, ist die Visceralschlinge erst im Beginn der Detorsion, und außerdem besitzen die in diese Familie gehörigen Arten noch einen Deckel (Operculum), wie das bei den Streptoneuren meistens der Fall ist. Von den Cephalaspideen sind mehrere Ordnungen von euthyneuren Sehnecken unmittelbar abzuleiten. Da sich innerhalb der Cephalaspideen die Rückdrehung der Visceralschlinge graduell bis zur vollstāndigen Detorsion vollzieht, können auch ihre $A b$ kömmlinge jeweils von verschiedenen Stadien herkommen. Von Formen ähnlich der Actaeonidae müssen die Basommatophora in der Gezeitenzone entstanden sein (C. R. Boettger: Basommatophora. In: G. Grim pe und E. Wagler: Die Tierwelt der Nord- und Ostsee. Teil IX. b 2. Lief. XXXV. Leipzig 1944). Die Stylommatophora stehen dem Ursprung der Basommatophoren aus den Cephalaspideen wahrscheinlich nicht sehr fern. Die pelagisch lebenden Thecosomata haben sich von Cephalaspideen mit fortgeschrittenerer Detorsion entwickelt. Auch bei den Oncidiacea ist die Visceralschlinge vollständig rückgedreht, weshalb sich die Gruppe wohl selbständig von entsprechenden Cephalaspideen in der Gezeitenzone gebildet hat. Fs ist vielleicht bemerkenswert, da $B$ unter den Euthyneuren ein Deckel (Operculum) auBer bei den Actaeoniden (Cephalaspidea) noch bei den Amphiboliden (Basommatophora) sowie den Spiratelliden und Peracliden (Thecosomata) vorkommt. 
Die übrigen von mir unterschiedenen Ordnungen der Euthyneuren leiten sich ebenfalls direkt oder indirekt von Cephalaspideen $a b$. Die früher mit den Thecosomata zu den „Pteropoda" vereinigten ebenfalls pelagisch lebenden Gymnosomata sind nicht unmittelbar aus den Cephalaspideen, sondern aus den A plysia ce a entstanden. Die von der Wurzel am weitesten entfernten Euth yneura sind zweifellos die Nudibranchia, die alle eine vollständig aufgehobene Streptoneurie haben. Sie besitzen auch keinerlei Schale mehr, sind aber von den meist noch beschalten Notaspidea abzuleiten.

21) Nachdem bereits frühere Bearbeiter von Arten der Oncidiidae darauf hingewiesen haben, daß diese Gruppe gegenüber den Stylom matophora, zu denen sie meist gestellt worden ist, zahlreiche Besonderheiten aufweist, ist jetzt nach den Untersuchungen, die V. Fretter über die Morphologie und Embryologie von Onchidella celtica Forbes and Hanley durchgeführt hat, eine solche systematische Verbindung nicht mehr möglich (V. Fretter: Studies in the functional morphology and embryology of Onchidella celtica (Forbes and Hanley) and their bearing on its relationships. Journ. Marine Biol. Assoc. United Kingdom. Vol. XXV (N. S.). No. 4. Cambridge 1943. pag. $685-720$ ). Wie bei anderen Oncidiiden ist auch bei Onchidella celtica Forbes and Hanley die Streptoneurie des Nervensystems aufgehoben; die Vorkammer des Herzens liegt in bezug auf die Kriechrichtung der Schnecke hinter der Herzkammer, und die Lage der Mantelhöhle ist entsprechend. V. Fretter rechnet daher die schalenlosen Oncidiid ae nach der früheren Auffassung zu den „Opis tho branchia" und trennt sie von den sogenannten ,Pulmonata". Das ist sicher richtig. Meines Erachtens sind die Oncidiiden von Cephalaspideen abzuleiten und zwar von Formen, bei denen die Streptoneurie bereits vollständig aufgehoben war. Auf alle Fälle waren bezüglich der Rückdrehung der Visceralschlinge die Ahnen der Oncidiidae erheblich weiter vorgeschritten als die Formen von Cephalaspideen, von denen die Basommatophoren und Stylommatophoren abzuleiten sind. Zweifellos können die Oncidiiden nicht mit den Stylommatophoren vereinigt werden; letztere sind bezüglich der Lage der Mantelhöhle meist noch prosopneumon, die Oncidiiden dagegen schon durchaus opisthopneumon. DaB beide Gruppen mit der Mantelhöhle atmosphärische Luft atmen, ist eine konvergente Ausbildung, die sich noch bei mehreren Gruppen innerhalb der Streptoneura wie Euthyneura unabhängig herausgebildet hat. Auch die retraktilen Fühler mit den endständigen Augen haben Oncidiiden und Stylommatophoren offenbar jede Gruppe selbständig entwickelt; schon bei einigen anderen Gastropoden-Gruppen trifft man auf die Tendenz eines Heraufrückens der Augen auf die Fühler (z.B. Otina); allerdings sind diese noch nicht retraktil. Ferner ist die Verkürzung der Visceralschlinge im Nervensystem ein Charakter, der innerhalb der Euthyneura bekanntlich nicht auf Stylommatophoren und Oncidiiden beschränkt ist. Man findet diese Besonderheit auch noch bei einer Anzahl von Basommato. phoren und zahlreichen Nudibranchiern. Ich halte für systematisch richtig, die Oncidiidae als besondere Ordnung. Oncidiacea der Euthyneura anzuerkennen, die ebenso wie die pelagischen Thecosomats von 
fortgeschritteneren Cephalaspideen abzuleiten sind, als das bei den Basom matophora und Stylommatophora der Fall ist.

${ }^{22}$ ) Die meistens gebrauchte Bezeichnung Decapoda für eine Ordnung der dibranchiaten Cephalopoden ist wegen der Verwendung dieses Namens für die zehnfüßigen Krebse, eine Unterordnung innerhalb der Malacostraca, nicht statthaft. Ich führe für die Ordnung der Tintenfische den neuen Namen Decabrachia ein und ersetze durch ihn den Namen Decapoda innerhalb der Cephalopoda. SinngemäB ist dann auch der Name Octopoda für die Kraken in Octobrachia zu ändern und Palaeoctopoda in Palaeoctobrachia.

23) Die früher als primitive Gruppe an den Anfang der Anneliden gestellten A rchiannelida sind nach neuen Untersuchungen sekundär vereinfachte Polychaeten. Da der Name allgemein eingebürgert ist, mag er der Gruppe als Ordnung der Polychaeten belassen bleiben.

24) Die Leibeshöhle der Priapuliden ist ein einheitliches Coelom mit peritonealer Auskleidung. Trotzdem keine Metamerie nachweisbar ist, ist kaum daran zu zweifeln, daß die Gruppe zu den Anneliden gehört.

25) Wenige fossile Formen aus dem Algonkium und Kambrium mit wurmförmigem Körper und zahlreichen Extremitätenpaaren werden wohl richtig mit den lebenden Malacopoden in Verbindung gebracht. Da die fossilen Arten marine Formen waren, sind wahrscheinlich die Malacopoden erst später zu Landtieren geworden, woraus sich die in diesem extremen Biotop herausgebildete cänogenetische Abkürzung des Entwicklungsganges und die teilweise komplizierte Brutpflege (Ausbildung einer bei südamerikanischen Arten vorkommenden Placentabildung, mit der der Embryo dorsal durch einen Strang verbunden ist) herleiten dürften. Marine Arten sind seit dem Palaeozoikum ausgestorben.

26) Die für diesen Subkladus oft gebrauchte Bezeichnung „Branchiata“", die wenig charakteristisch ist und Anlaß zu Verwechslungen sein kann, soll durch ,Diantennata“" ersetzt werden.

${ }^{27}$ ) Die systematische Stellung der nur aus dem mitteleuropäischen Unterdevon bekannten Gattung Cheloniellon erscheint nicht endgültig geklärt. Das Tier zeichnet sich durch seine verbreiterte, rundliche Körperform aus, dio oberflächlich an eine Schildkröte erinnert. Da bisher keinerlei nähere Verwandtschaftsbeziehungen ermittelt werden konnten, fügt man sie am zweckmäßigsten als besondere Klasse an der angegebenen Stelle ein.

$\left.{ }^{28}\right)$ Über die systematische Gliederung der Anostraca und Phyllopoda hat neuerdings G. Preuss gründliche Untersuchungen angestellt (G. Preuss: Die Verwandtschaft der Anostraca und Phyllopoda. Zool. Anzeig. Bd. 147. Leipzig 1951. pag. 49-64). Den Ergebnissen ist beizupflichten.

${ }^{29}$ ) In die Gruppe Onychura hat S. Eriksson die Conchostraca mit den Cladocera vereinigt (S. Eriksson: Studien über die Fangapparate der Branchiopoden nebst einigen phylogenetischen Bemerkungen. Zool. Bidrag Cppsala. Bd. 15. Uppsala 1934. pag. 23-287).

30) Es handelt sich bei den Marriocarida um bisher noch nicht hinreichend bekannte Krebse aus dem Palaeozoikum, die wohl in eine besondere Unterklasse zu stellen sind.

31) Die Marrellomorphen zeichnen sich durch lange, gegliederte Spaltbeine und 
einfache Gehbeine, sowie schwankende Segmentzahl aus. Sie sind mit keiner der lebenden Gruppen in nähere Verbindung zu bringen, so daß für sie die Aufstellung einer besonderen Unterklasse wohl notwendig ist.

32) Die Karpfenläuse (Bränchiura) nähert man wohl am besten der Wurzel der Copepoden, von der sie sich wahrscheinlich in Zusammenhang mit der Art ihrer parasitischen Lebensweise stark spezialisiert haben. Deshalb stelle ich sie als besondere Ordnung in die Unterklasse Copepoda hinter die Eucopepoda.

${ }^{33}$ ) $=$ Leptostraca. $\left.{ }^{34}\right)=$ Anomostraca.

35) Bisher nahm man an, daß zwischen den Isopoda und Amphipoda enge Verwandtschaftsbeziehungen beständen. Nach kürzlichen Untersuchungen von R. Siewing ist das jedoch nicht der Fall. Vielmehr müssen innerhalb der Peracarida Isopoden und Amphipoden als Endglieder zweier frühzeitig getrennter Reihen angesehen werden (R. Siewing: Besteht eine engere Verwandtschaft zwischen Isopoden und Amphipoden? Zool. Anzeig. Bd. 147. Heft 7-8. Leipzig 1951. pag. 166-180).

$\left.{ }^{36}\right)=$ Stomatopoda.

37) Bemerkenswert ist, daß bei den Palaeopantopoden aus dem Devon das Abdomen noch nicht so stummelförmig geworden ist wie bei den lebenden Eupantopoden.

38) Die Linguatuliden sind zweifellos infolge ihrer parasitischen Lebensweise sekundär in ihrer Organisation vereinfacht und wieder wurmförmig geworden. Die Cuticula dieser Tiere entspricht der der Arthropoden; auch enthält sie Chitin. Die Muskulatur der Linguatuliden ist quergestreift, wie das bei den Arthropoden mit Ausnahme der Malacopoden fast allgemein der Fall ist; bei Anneliden kommt dagegen quergestreifte Muskulatur nur vereinzelt vor. Auch im Bau der Genitalorgane sind die Zungenwürmer den Arthropoden sicher ähnlicher als den Anneliden. Die Linguatuliden werden auf Grund ihres Entwicklungsganges wohl zweckmäBig den Cheliceraten eingegliedert, wo sie sicher in eine besondere Klasse gehören. Mit den Arachnoidea bestehen keine engeren Beziehungen, und der gelegentlich auf Grund des gestreckten Hinterleibes versuchte Vergleich mit gewissen Acarinen beruht zweifellos auf Konvergenz.

39) Innerhalb der Ephemeroidea wird neben den Ephemerida meist noch eine ausgestorbene Ordnung Protephemerida unterschieden. Sicher zeigt die altertümliche Art Triplosoba pulchella Brongniart aus dem Oberkarbon einen Körperbau, der die Ephemeriden mit den Palaeodictyopteren verbindet, denen sie wohl entsprossen sind. Aber die Aufstellung einer besonderen Familie Triplosobidae innerhalb der Ephemerida genügt wohl. Neben der anch in der Gegenwart recht ursprïngliche Züge anfweisenden Ordnung Ephemerida halte ich daher die Abtrennung einer Ordnung Protephemerida nicht für notwendig.

40) Das im tropischen Afrika in dem Fell eines Nagers (Cricetomys) parasitisch lebende Insekt Hemimerus talpoides Walk. rechnet man meistens in eine besondere Ordnung Diploglossa ta. Ich sehe in der Art einen durch seine Lebensweise veränderten Verwandten der Dermapteren, für den die Aufstellnng einer Unterordnung Hemimerine neben den Forfi culinea innerhalb der Ordnung Dermaptera genügt. 
41) Neuerdings hat $R$. Jeannel die meistens rertretene Ansicht einer Verwandtschaft der im weiblichen Geschlecht parasitischen Fächerflügler Strepsiptera mit den Käfern (Coleoptera) abgelehnt und die Strepsipteren als Ordnung zu den Hymenopteroidea gestellt. Ich möchte einstweilen die frühere Klassifikation beibehalten, bis eine Nachprüfung erfolgt ist.

42) Im Jahr 1933 hat P. Uschakow ein eigenartiges Tier in mehreren Exemplaren aus den Tiefen des Ochotskischen Meeres untersucht, die Art als neu erkannt und sie unter dem Namen Lamellisabella zachsi Uschakow als Vertreter einer neuen Gattung beschrieben, die er in die PolychaetenFamilie Sabellidae stellte (P. Uschakow: Eine neue Form aus der Familie Sabellidae (Polychaeta). Zool. Anzeig. 104. Bd. Leipzig 1933. pag. 205-208). K. E. Johansson konnte die Anatomie nachprüfen und kam zu dem Ergebnis, daB es sich zweifellos nicht um einen Angehörigen der Sa bellidae, überhaupt kaum um einen Polychaeten handelt. Da auch ein versuchter Vergleich mit den Phoronidea zu keinem befriedigenden Ergebnis führte, stellte K.E. Johansson für die Art eine neue Tiergruppe auf, die er Pogonofora benannte (K. E. Johansson: Über Lamellisabella zachsi und ihre systematische Stellung. Zool. Anzeig. 117. Bd. Leipzig 1937. pag. 23-26). Es ist nun das Verdienst W. Ulrichs, erneut auf die kaum mehr beachtete Art hingewiesen und ihre systematische Stellung auf Grund der immerhin lückenhaften Beschreibungen geklärt zu haben (W. Ulrich: Über die systematische Stellung einer neuen Tierklasse (Pogonofora K. E. Johanisson), den Begriff der Archicoelomaten und die Einteilung der Bilaterien. Sitzungsber. Deutsch. Akad. Wissensch. Berlin. Mathem.-naturw. Kl, Jg. 1949. Nr. II. Berlin 1950). Nach eingehender kritischer Wertung der über Lamellisabella gemachten Angaben kommt auch W. Ulrich zu dem Schluß, daß das.in einer geraden, halmartigen, bis $30 \mathrm{~cm}$ langen Röhre von nur $2 \mathrm{~mm}$ Durch messer lebende wurmförmige Tier von $14 \mathrm{~cm}$ Länge kein Polychaet sein kann, denn es hat keine Borsten, kein Bauchmark und keine Konnektive, im Ganzen nichts, was für eine echte Metamerie spricht. Überzeugend vergleicht aber W. Ulrich die Organisation von Lamellisabella mit der der Branchiotremata. Beide haben die charakteristische Dreiteilung des Körpers und besitzen große praeorale Körperabschnitte; auch die bei Lamellísabella zu beobachtende Betonung der Dorsalseite in der Ausbildung des Nervensystems und dessen subepitheliale Lage sprechen für derartige Verwandtschaftsbeziehungen, die noch durch weitere Utbereinstimmungen unterstrichen werden. $W$. Ulrich hat sich entschlossen, die Pogonofora als selbständigen Stamm in seine neben Protostomia und Deuterostomia innerhalb der Bilateria anterschiedenen Archicoelomata zu stellen und zwar zwischen die Stämme der Branchiotremata und Tentaculata. Im Text dieser Arbeit (pag. 259 - 260) ist bereits darauf hingewiesen worden, da B ich mich mit dieser Aufstellung einer Gruppe der A rchicoelomata nicht einverstanden erklären kann. Die Branchiotremat a sind Deuterostomier, während die Tentaculaten auf Grund der Spiralfurchung ihres Keimes und der Ausbildung einer Larve im Typ der Trochophora-Larve eindeutige Protostomier sind, woran auch die an die Verhält- 
nisse bei dem anderen Phylum erinnernde Faltung des Mesoderms nichts ändern kann. Ich möchte die Pogonofora (die Schreibweise des Namens ist wohl besser in Pogonophora zu ändern) nicht so scharf von den Branchiotremata trennen und in ihnen keinen neuen Stamm sehen. Auf Grund der von W. Ulrich diskutierten anatomischen Verhältnisse von Lamellisabella halte ich die Pogonophora für eine besondere Klasse der Branchiotremata, die ich zwischen die Klassen der Entero. pneusta (Eichelwürmer) und der Pterobranchia (Flügelkiemer) stelle.

13) Die vom Kambrium bis in das Karbon lebenden Edrioas teroidea stellt man zweckmäßig als besondere Klasse neben die Cystoidea. Die fünfstrahligen Tiere haben weder Arme noch Stiel, welche Teile allerdings auch bei manchen Cystoideen fehlen können oder nur schwach entwickelt sind. Doch sind bei den Edrioasteroideen die zahlreichen Einzelplatten des Körpers niemals fest verbünden. Es hat den Anschein, als ob die Edrioasteroidea die Stammformen der Eleutherozoa sind. Wie bei den übrigen Pelmatozoa liegt aber auch bei den bekannt gewordenen Edrioasteroideen der After noch exzentrisch interradial an der oralen Seite, weshalb sie durchaus als Vertreter dieses Subkladus der Echinodermaten anzusehen sind.

44) Die rom Silur bis ins Karbon vertretenen Auluroidea haben SeesternHabitus mit wohlentwickelten 5 Armen. Doch fungiert bei ihnen als Madreporenplatte eines der Mundschilder wie bei den Schlangensternen (Ophiu roidea), im Gegensatz zu den Verhältnissen bei den Seesternen (Astero. idea), wo die Madreporenplatte interradial auf der Apicalseite liegt. Offenbar bestehen also trotz der äußeren Erscheinung nähere systematische Beziehungen zu den Ophiuroideen. Es erscheint also zweckmäBig, die Auluroidea als besondere Klasse innerhalb der Eleu therozoa neben die 0 phiu roidea zu stellen.

45) Bei den Agnathi, den primitivsten Vertebraten, sind sämtliche Visceralbögen noch Kiemenbögen. Eine Gegenüberstellung der ungepanzerten und gepanzerten Arten erscheint systematisch nicht gerechtfertigt. Die im Silur und Devon in mehreren Ordnungen vertretenen kieferlosen Vertebraten erlöschen am Ausgang dieser Periode mit Ausnahme der Rundmäuler (Cyclostomata), die sich bis in die Gegenwart erhalten haben.

46) Im Gegensatz zu den Agnathen ist bei den Urfischen der 1. Viscaralbogen, hinter dem eine gut ausgebildete Kiemenspalte liegt, bereits als Kiefer. bogen spexialisiert; deshalb können auch bei verschiedenen Arten schon Zahnbildungen auftreten. De- 2. Visceralbogen ist sber noch wicht zum Suspensorium des Kieferbogens geworden, wie das bei den eigentlichen Fischen (Pisces) der Fall ist.

Diese Klasse wird oft als Placodermi bezeichnet, doch trifft diese Benennung als Panzerfische nicht für alle Ordnungen zu. Da als Charakteristikum dieser Klasse die Verhältnisse am Visceralskelett gelten, ist dem Namen Aphetohyoidea der Vorzug zu geben. Vertreter der Erfische treten im Silur auf und erlöschen bereits wieder im Perm.

47) Nachdem die Quastenflosser (Crossopterygii) lange Zeit als ausgestorben gegolten hatten, konnte im Dezember 1938 an der südafrikaniechen Küste in Latimeria chalumnae J. L. B. Smith ein lebender Vertreter dieser 
Fische gefangen werden. Die Art gehört in die Unterordnung Actinistia. Die wie diese ebenfalls im Devon auftretende andere Unterordnung Rhipidistia ist im Karbon erloschen. Aus Rhipidistiern haben zweifellos die Amphibien ihren Ursprung genommen, nicht etwa aus Lungenfischen (Dipnoi), wie früher vielfach vermutet wurde.

48) Nach unserer derzeitigen Kenntnis der fossilen Amphibien ist es nicht mehr angāngig, eine einheitliche Ordnung der ,Stegocephalen" neben den 3 lebend vorkommenden Ordnungen anzunehmen. Die ausgestorbenen Arten sind vielmehr untereinander mindestens ebenso verschieden wie die rezenten. Innerhalb der Amphibien lassen sich deutlich 2 Gruppen unterscheiden, die ich hier als Unterklassen auffasse. F. Frhr. v. Huene ist der Ansicht, daß beide Gruppen sogar verschiedenen Ursprungs sind (F. Frhr.r. Huene: Die Saurierwelt und ihre geschichtlichen Zusammenhänge. Jena 1952). Nach ihm sollen die Urodelomorpha (= Lepospondyli) aus der Superfamilie Porolepif ormes des zu den Crossopter ygii gehörigen Subordo Rhipidistia entsprossen sein, die Batrachomorphoidea (= Apsidospondyli) dagegen aus der in dieselbe Unterordnung gehörigen Superfamilie Osteolepiformes. Die Amphibien wären dann also diphyletischen Ursprungs und müßten als systematische Klasse aufgelöst werden. Doch halte ich weitere Untersuchungen über diese immerhin möglichen Zusammenhänge für erforderlich, weshalb ich einstweilen die einheitliche Klasse beibehalte.

49) Die Blindwühlen (Gymnophiona) sind auf die Tropen beschränkt. Fossile Reste dieser Ordnung hat man bisher noch nicht gefunden. Unter Berücksichtigung des Wirbel- und Schädelbaues scheinen sie mit den Aistopoda in Verbindung zu stehen.

50) Die vom Karbon bis zum Unterperm vertretenen Microsauria werden oft zu den Reptilien gerechnet. Zweifellos haben sie mancherlei Beziehungen zu den Cotylosauria, die an den Anfang der Reptilien zu stellen sind. Leider kennt man den biologischen Entwicklungsgang bei diesen Arten nicht und kann vor allem nichts über die Bildung der Eihäute wissen: so ist man auf Vermutungen angewiesen. Nach meiner Ansicht sind die sicher recht primitiv gebauten Microsaurier besser noch zu den Amphibien zu rechnen, und der doch stets künstliche Schnitt zwischen den beiden Klassen ist hinter den Microsauria zu machen.

51) Die Apsidospondyli sind offenbar eine eng umrissene Einheit, aus der keinerlei höher entwickelte Vertebraten-Gruppe hervorgegangen ist. Die noch in der Gegenwart häufige Ordnung der Frösche (Salientia) schließt. sich wahrseheinlich über die Proanura an die Unterordnung Rhachitomi der Labyrinthodontia an. Die aus dem Buntsandstein Madagaskars stammende, zu den Proanuren gehörige Gattung Protobatrachus soll sogar unmittelbar mit der oberkarbonischen Gattung Amphibamus, einem Vertreter der Rhachitomi, zusammenhängen. Eine Entwicklung der Salientia aus Proanuren ist aber mit Sicherheit anzunehmen.

$\left.{ }^{52}\right)$ Eine Klassifikation der R eptilia auf möglichst natürlicher Basis geschieht zweckmāBig auf Grund der Ausbildung der Schläfenregion des Schädels. Ich unterscheide dementsprechend 5 Unterklassen der Reptilien. Der primitivste Zustand ist der cines geschlossenen Schädeldaches ohne 
Schläfenöffnung (Subcl. Anapsida). Mit fortschreitender Entwicklung der Kiefermuskulatur können nun bei verschiedenen Reptiliengruppen solche Öffnungen an bestimmten Stellen gebildet werden. Eine einzige Schläfenöffnung zwischen Postfrontale und Supratemporale entsteht bei der Subcl. Metapsida. Ebenso kann eine Schläfenöffnung zwischen Postorbitale und Squamosum entwickelt werden (Subcl. Synapsida). Ferner können 2 Temporalöffnungen auftreten, getrennt durch Squamosum und Postorbitale (Subcl. Diapsida). Diese 3 erwähnten, als Cnterklassen angesehenen Gruppen mit Schläfenöffnungen haben sich zweifellos unabhängig voneinander aus primitiven Reptilien mit geschlossenem Schädeldach entwickelt. Eine weitere Gruppe kann dadurch unterschieden werden, daß bei dem diapsiden Zustand der untere Sehläfenbogen (Quadratojugale + Jugale) reduziert wird; es entsteht dann sekundär wieder nur eine Schläfenöffnung (Subcl. Katapsida). Diese letzte Unterklasse der Reptilien geht gleitend aus den Diapsida hervor. Ich möchte zu den Katap. sida sogar bereits die Brückenechsen Rhynchocephalia mit noch deutlich 2 Schläfenöffnungen rechnen; doch zeigt bei Vertretern dieser Ordnung der Schädelbau schon Abänderungen, die eine Verwandtschaft z: Gruppen mit katapsidem Zustand der Schläfenregion deutlich erkennen lassen.

Innerhalb der Reptilien beginnt bei einigen Gruppen sich eine Homoiothermie herauszubilden. Bei der Mehrzahl der Tiere findet bekanntermaBen ein Wärmeaustausch des Körpers mit der Umgebung so rasch und so roll. ständig statt, daß die bei dem Lebensprozeß erzeugte Wärme im allge. meinen schnell verlorengeht und nur noch gelegentlich bei starken Arbeits. leistungen eine Übertemperatur für kurze Zeit erreicht wird (z. B. lebhafte Flügelbewegung bei Schmetterlingen, erhebliche Muskelanstrengung bei Fischen). Sowohl bei den höchstentwickelten Gruppen der Protostomier wie der Deuterostomier gewinnt aber eine Wärmeerzeugung zuweilen Bedeutung für den Lebensablauf. Bekannt ist der soziale Wärmehaushalt der Bienen und einiger anderer staatenbildender Hymenopteren. Bei den bereits erwähnten Schmetterlingen (Lepidoptera) kann vor dem Abflug ein Schwirren von je nach der Außentemperatur verschieden langer Dauer stattfinden, bis die Abflugstemperatur erreicht wird. Unter den lebenden Reptilien soll nun eine geringe Erhöhung und Regelung der Körpertemperatur bei einigen Riesenschlangen (Python) in Zusammenhang mit der Brutpflege vorkommen, indem die Weibehen nach der Eiablage eine zeitweise über der Außentemperatur liegende Körperwärme aufweisen und sich über ihren Eiern zusammenrollen. Unter den zahlreichen fossilen Reptilien ist eine Warmblütigkeit mindestens bei 3 verschiedenen Gruppen unabhängig entstanden. Finmal muB das bei den $S$ yn apsida an der Grenze der Therapsiden zu den Säugetieren (Mammalia) der Fall gewesen sein. Ferner ist an 2 Stellen innerbalb der Diapsida ein Utbergang zur Homoiothermie bei der Ausbildung von Flugtieren erfolgt und zwar bei den offensichtlich aus Pseudosuchia entwickelten Vögeln (Aves) sowie bei den Flugsauriern (Pterosauria). Da nämlich der Körper der Pterosaurier behaart gewesen ist, muB man annehmen, da 8 die Tiere warmblütig waren. Ob noch weitere Gruppen fossiler Reptilien einer Wärmeentwicklung fähig waren, ist nicht mehr festzustellen; in der Mehrzahl waren sie es 
wahrscheinlich nicht. Doch ist bemerkenswert, daß die beiden aus Reptilienartigen Vorfahren hervorgegangenen Klassen der Säugetiere (Mam malia) und Vögel (Aves) dieses Vermögen weiterentwickelt haben. In der Gegenwart ist die mittlere Körpertemperatur bei den Vögeln mit $41-42^{\circ}$ am höchsten; auch kann die Übertemperatur des Körpers gegenüber der Cmwelt beträchtlich sein und bei Polarvögeln bis $80^{\circ} \mathrm{C}$ betragen (bei Außentemperaturen bis $\mathrm{zu}-40^{\circ} \mathrm{C}$ ).

53) Die Seymouriamorpha, vertreten im Oberkarbon und im Perm, werden manchmal zu den Amphibien gerechnet. Ich sehe in der Gruppe die primitivste Unterordnung der Cotylosauria.

54) Die Eunotosauria aus dem südafrikanischen Mittelperm hat man vielfach mit den Schildkröten (Testudines) in Verbindung bringen wollen. Doch scheint es sich um eine selbständige, konvergent ausgebildete Gruppe zu handeln, die nur durch ihre verbreiterten Rippen Schildkröten-ähnlich aussieht; ihr fehlen die den Neuralplatten des Panzers ansitzenden echten Costalia der Schildkröten.

55) Die ältesten bekannt gewordenen Ichthyosaurier, die in der Trias vorkommende Gattung Mixosaurus, haben erst eine sehr kleine Öffnung zwischen Postfrontale und Supratemporale. Die Ichthyosaurier sind zweifellos aus Cotylosauriern entstanden, die wohl den Diadectomorpha nahegestanden haben müssen.

56) Die vom Oberkarbon bis in die Trias lebenden Pelycosaurier sind sicher die primitivsten Synapsida. Sie sind wohl aus Cotylosauria entstanden, unter denen sie sich an die Unterordnung Captor hin o mor $\mathrm{h}$ a anschließen dürften.

57) Die Ordnung der Therapsida ist eine außerordentlich formenreiche Gruppe; sie hat sich wohl aus Pelycosauriern des Subordo Sphenacodontia entwickelt. Die Therapsiden sind für uns deshalb von besonderer Bedeutung, weil aus ihnen die Säugetiere (Mammalia) ihren Ursprung genommen haben müssen. Die Vermutung, daß die Entstehung der Homoiothermie in einem direkten Zusammenhang zur Perm-Eiszeit steht, hat wohl eine gewisse Berechtigung (C. R. Boettger: Wo sind die Säugetiere entstanden? Sitzungsber. Ges. Naturforsch. Freunde Berlin. Jg. 1938. Nr. 1-3. Berlin 1938. pag. 24-30). Die eigenwarmen Säugetiere sind auch biologisch als unmittelbare Fortsetzung der Therapsiden anzusehen, die sie allmählich ersetzt haben, bis die letzten Reptilien dieser Ordnung im mittleren Dogger erloschen sind.

58) Die vom Perm bis in die Trias vertretenen Thecodontia sind zweifellos die primitivsten Vertreter der Diapsida. Mit ihrer Unterordnung Fosu chia reichten sie als einzige Gruppe der Diapsiden noch ins Paläozoikum; alle übrigen Finheiten treten erst mesozoisch auf. Die wichtigste Gruppe der Thecodontier sind zweifellos die aus Eosuchiern weiterentwickelten Pseudosuchia, denn aus ihnen sind nicht allein die übrigen Ordnungen der Diapsiden mit ihren überaus auffälligen, teils riesengroßen Formen entstanden, sondern auch die systematisch als besondere Klasse zu wertenden Vögel (Aves).

59) Die Saurischia wurden fräher mit den Ornithischis unter dem bekannten Namen der Dinosaurier vereinigt. Jetzt werden sie wohl allgemein 
als gesonderte Ordnungen angesehen. Die Saurischia sind Raubtiere, die Ornithischia dagegen herbivor. $\mathrm{Zu}$ den Saurischiern gehören die größten Landtiere, die jemals gelebt haben (bis $22 \mathrm{~m}$ länge).

60) Wie bereits in Anmerkung 52 angegeben, mache ich den Schnitt zwischen Diapsida und Katapsida nicht hinter, sondern vor den Rhynchocephalia, rechne also diese zu den Katapsiden überleitende Gruppe trotz des diapsiden Zustandes ihrer Schläfenregion bereits zu den Katapsida. Diese Cnterklasse der Reptilien trennt sich schon im Perm von Eosuchia ab.

61) Die Anpassung der Vögel (Aves) an die fliegende Lebensweise hat auch die Fortpflanzungsbiologie dieser Tiere wesentlich beeinfluBt. Die relativ großen Eier werden rasch gebildet und verlassen den mütterlichen Organismus in kurzer Zeit, wodurch der Vogel möglichst wenig im Flug behindert wird. Die großen Eier, die alle für den Embryo benötigten Nahrungsstoffe in ausreichendem $\mathrm{MaB}$ enthalten, machen die Entwicklung von einer Nahrungszufuhr unabhängig. Eine harte Kalkschale, nur für Gase (Sauerstoff und Kohlendioxyd) durchlässig, konnte daher das $\mathrm{Ei}$ schützen. Diese Kalkschale machte es auch möglich, daß die homoiotherm gewordenen Vögel die Entwicklung der Eier durch Bebrüten beschleunigten. Das Legen der großen Vogeleier bedingte anatomische Besonderheiten im Bau des bereits durch die Bipedie veränderten Beckens.

62) Es ist das Verdienst von E. Stresemann, mit der überlieferten Klassifikation der Vögel, die hauptsächlich auf die europäische Ornis zugeschnitten war, endgültig gebrochen zu haben, indem er zunächst eine große Zahl kleinerer natürlicher Einheiten aufstellte (E. Stresemann: Sauropsida: Aves. In W. Kükenthal: Handbuch der Zoologie. VII. Bd. 2. Hälfte. Berlin u. Leipzig 1927-1934). So sorgfältig in der Ornithologie auch die Systematik von Arten und Familien begründet ist, so lückenhaft sind doch einstweilen die Erkenntnisse für die Aufstellung böherer Einheiten. Auf Grund überragender Formenkenntnis und Beherrschung des Stoffes haben erst kürzlich E. Mayr und D. Amadon unternommen, einige Vogelgruppen enger zusammenzufassen (E. Mayr and D. Amadon: A Classification of Recent Birds. Americ. Mus. Novitates. No. 1496. New York 1951). Im allgemeinen bin ich ihnen in der Systematik gefolgt.

${ }^{63}$ ) Auf Grund der neuerlich festgestellten nahen Verwandtschaft der auf dem Nandu (Rhea americana L.) vorkommenden Mallophagen (W. Eichler: Ektoparasiten von Zoo-Tieren. I. Mallophagen vom Nandu. Zoolog. Garten. Neue Folge. XVII. Bd. Leipzig 1950. pag. 258-261) mit den auf den Struthio-Arten lebenden Federlingen kann an einer engen Zusammengehörigkeit der beiden genannten Ratiten-Gattungen nicht mehr gezweifelt werden. Die zoogeographischen Zusammenhänge der einzelnen Struthioniformes und die Verwandtschaftsbeziehungen der rezenten wie der fossilen in Betracht kommenden Formen bleibt zu untersuchen. Unter den lebenden Arten sind offensichtlich die amerikanischen StrauBe primitiver als die Struthio-Arten.

64) Bei den Phororhaci handelt es sich um Reste großer, zum Teil sogar riesiger Vögel aus dem südamerikanischen Tertiär. Die Fundschichten sind wahrschemlich in das Oligozän und Miozàn einzustufen. Die Phoro- 
rhaci umfassen mehrere Gattungen, die wohl in 3 Familien zusammenzufassen sind. Eine Übersicht über die einzelnen Arten hat K. La mbrecht gegeben (K. Lambrecht: Handbuch der Palaeornithologie. Berlin 1933. - A. Wetmore: Recent Additions to our Knowledge of Prehistoric Birds 1933-1949. Proc. X. Internation. Ornithol. Congress. Uppsala and Stockholm 1951. pag. 51-74). Systematisch sind die Phororhaci offenbar den Cariamae zu nähern, neben die ich sie als besondere Unterordnung innerhalb der Gruiformes stelle. Die Cariamae selbst sind im südamerikanischen Unterpliozän in den beiden Gattungen Procariama Rovereto und Hermosiornis Rovereto vertreten.

65) Die eigenartigen Riesenvögel der Gattungen Diatryma Cope und Omorhamphus Sinclair aus dem Untereozän Nordamerikas und Europas, die zusammen in eine Familie Diatrymidae gehören, sind wahrscheinlich als besondere Ordnung Diatrymiformes neben die Gruiformes zu stellen. Sie erinnern an die südamerikanische Unterordnung Phororhaci der Gruiformes, vor allem durch die Gestalt des Schädels, was aber doch wohl als Konvergenzerscheinung in Zusammenhang mit einer ähnlichen Ernährungsweise zu werten ist.

$\left.{ }^{66}\right)$ Alle rezenten Monotrematen haben als erwachsenes Tier zahnlose, mit Horn überzogene Kiefer. $\mathrm{DaB}$ es sich dabei nicht um einen ursprünglichen $\mathrm{Zu}$ stand handelt, wird dadurch bewiesen, daß Ornith orh ynch us im Jugendstadium noch auf jeder Seite des Oberkiefers 4 und des Unterkiefers 3 Zähne besitzt. Diese Zähne haben nur eine kurze Wurzel und eine breite, flache multituberkulare Krone. Durch den Gebrauch werden die Zähne allmählich abgerieben, worauf die Wurzel resorbiert wird und der Kiefer verhornt. Bezeichnend ist nun, daß dieses Jugendgebiß von Ornithorhynchus aus multituberkularen Zähnen besteht. Zwar konnte man keine vollständige Identitāt dieser Bezahnung mit dem Gebiß der verglichenen frühtertiären Multituberculata feststellen, was wohl bei der Mannigfaltigkeit in der Ausbildung multituberkularer Gebisse recht wenig besagt. Meiner Ansicht nach kann an einem engen Zusammenhang der Monotremata mit den Multituberculata nicht gezweifelt werden; die Monotrematen stellen nur einen aberranten Zweig dieser alten Gruppe dar, der sich unter besonderen Verhältnissen bis in die Gegenwart erhalten konnte.

Bekanntlich legen-als einzige Vertreter der Säugetiere der Gegenwart die Monotremata noch Eier. Es muB sich also diese Fortpflanzungsweise von den Therapsida als mutmaBliche Vorfahren der Mammalia auf diese vererbt haben, und erst innerhalb der Säugetiere entwickelte sich die bei den spezialisierten Formen allgemein anzutreffende Art der Fortpflanzung durch Gebären von Jungen. Fine erste Brutpflege entstand wohl dadurch, daB sich die homoiotherm gewordenen Tiere auf die Eier setzten, wodurch diese Anteil an der erhöhten Temperatur hatten und in ihrer Entwicklung begünstigt wurden. Ein solches Bebrüten bildete sich unabhängig bei den beiden systematisch einander so fernstehenden homoiothermen Klassen der Vögel und Säugetiere. Während das Brüten bei der Fortpflanzung für die Vögel bis in die spezialisierten Gruppen bedeutsam blieb, entwickelte sich der Vorgang des Bebrütens der Eier bei den Säugetieren bald in einer anderen Richtung. Wir wissen heute, daß nämlich der 
für die Säugetiere so charakteristische Mammarapparat ursprünglich ein Brutorgan war, der erst durch Funktionswechsel später zu einem Milchorgan wurde. In frühen Entwicklungsstufen unserer höher entwickelten Säugetiere wird der spätere Mammarapparat in einer Form angelegt, die nur als ein Organ zum Bebrüten von Eiern zu erklären ist. Er entspricht auf dieser Stufe etwa dem bekannten Brutfleck der Vögel. Dieses sicher für die primitiven Mammalia anzunehmende Brutorgan entwickelte sich weiter durch reiche Entfaltung der Hautdrüsen zu dem Mammarapparat, der den ausgeschlüpften Jungen gestattete, die Absonderungen der Hautdrüsen als Nahrung zu verwerten. Da die Milchdrüsen bei den höheren Säugetieren aus acinösen Talgdrüsen, bei den heute lebenden Monotrematen aber aus tubulösen Schweißdrïsen gebildet worden sind, ist zu folgern. daß bei den primitiven Mammalia eine Spezialisierung in der einen oder anderen Richtung noch nicht stattgefunden hatte und vermutlich zunächst die Ausscheidungen sowohl von Schweiß- als auch von Talgdrüsen als Nahrung aufgenommen wurden.

Diese Brutpflege der Eier band das brütende Tier längere Zeit an einen bestimmten Platz. Ortsveränderungen konnte es vornehmen, wenn die Eier mitgeführt werden konnten, was in einer Hautfalte, dem sog. ,Beutel ${ }^{*}$. geschah. Unter den Monotrematen trägt Echidna ihr Ei im Beutel, während Ornithorhynchus brütet. Von diesem Stadium der Brutpflege ist es nicht weit, daB die Jungen schon aus dem Ei geschlüpft geboren werden und im Beutel Aufnahme finden. Bei den mannigfaltige Formen umfassenden Beuteltieren (Marsupialia) ist das stets der Fall. Der Grad einer Ausbildung des Beutels ist bei den einzelnen Gruppen recht verschieden weit fortgeschritten; eine zweifellos sehr primitive Form unter den lebenden Marsupialiern ist der beutellose Myrmecobius. Während bei den Beuteltieren die Jungen in noch sehr unentwickeltem Zustand geboren werden, kann bei den Placentalia durch die Placentabildung die Geburt in einem meist wesentlich späteren Stadium erfolgen. Schon bei den Beuteltieren kommen Formen mit Placentabildung vor (Dasyurus, Perameles). Durch die spätere Geburt der Jungen verliert der Beutel an Bedeutung, wird rückgebildet und ist bei den Placentaliern nicht mehr vorhanden. Daß jedoch die Placentalia aus primitiven Marsupialia abzuleiten sind, geht aus dem Vorkommen embryonaler Marsupialfalten als Rudimente bei vielen Placentaliern hervor.

67) Die kleine Säugetiere aus dem Jura umfassende Ordnung Pantotheria (= Trituberculata) dürfte wohl als Ausgangsgruppe sowohl der Marsupialia (Beuteltiere) als auch der Placentalia (Placentasäugetiere) zu gelten haben. Dagegen scheinen die ebenfalls jurassischen, nur in spärlichen Resten bekannten Symmetrodonta und Triconodonta sich nicht in späteren Säugetieren fortgesetzt zu haben.

68) Nach meiner Ansicht ist es nicht angängig, die ausgestorbenen alteren Carnivoren-Gruppen mit ihrer großen Formenmannigfaltigkeit geschlossen als eine Unterordnung "Creod ontia " svstematisch neben die jüngeren Raubtiergruppen za stellen. Die oft als besondere Einheit angesehenen Procreodi aus dem Paleozän und Eozän sind offenbar mit den eozänen A creodi eng verbunden, so daB sie als eine Cnterordnung zu gelten haben. 
Ihnen sind wohl die vom Paleozän bis ins Miozän vorkommenden Pse udocreodi und die im Eozän auftretenden, doch schon im Oligozän erlöschenden Eucreodi entsprossen. Aus den Eucreodi haben sich offensichtlich die beiden gegenwärtig noch fortbestehenden Unterordnungen A rct o idea und Aeluroidea unabhängig voneinander entwickelt. Die meist als besondere Unterordnung unterschiedenen „Pinnipedia" sind keine systematische Gruppe, da sie diphyletischen Ursprungs sind, wie das für den Unterschied zwischen den Phocidae und Otariidae bereits S. G. Mivart nachgewiesen hat (S. G. Mivart: Notes on the Pinnipedia. Proc. Zoolog. Soc. London. London 1885. pag. 484-50I). Ich bin kürzlich erneut auf diese Frage eingegangen (C. R. Boettger: Notizen zur Verbreitung und über die Verwandtschaftsbeziehungen der Mönchsrobbe (Monachus al bi venter Boddaert). Zool. Anzeig. Bd. 147. Leipzig 1951. pag. 303-310). Die Pinnipedier sind aus 2 verschiedenen Stämmen der Arctoidea entstanden, die sich dem Wasserleben angepaßt haben; sie müssen den Ar ctoidea zugerechnet und zwischen die außerdem noch unterschiedenen Familien gestellt werden (Fam. Canidae, Procyonidae, Ursidae, Otari idae, Odobenidae, Mustelidae, Phocidae).

$\left.{ }^{69}\right) \mathrm{Zu}$ den Perissodactyla gehören die größten landbewohnenden Säugetiere, die während des Miozäns lebenden, ausgestorbenen Arten der Gattung Baluchitherium Forster-Cooper, Verwandte der Nashörne: (Superfam. Rhinocerotoidea), jedoch ungehörnt; sie erreichten eine Schulterhöhe von über $5 \mathrm{~m}$, übertrafen also die Elefanten an Größe.

io) Es ist meines Erachtens nicht angängig, die Neuweltaffen (Platyrhina) mit den als Catarhina bezeichneten Altweltaffen (Pithecoidea) in einer systematischen Gruppe zu vereinigen, da beide Einheiten zweifellos vollständig unabhängig voneinander aus Halbaffen herrorgegangen sind. Ich stelle daher die Neuweltaffen als besondere Ordnung neben die Halbaffen und Altweltaffen. 